\section{OPEN ACCESS}

Edited by:

Juliana Campos Junqueira,

São Paulo State University, Brazil

Reviewed by:

Rohitashw Kumar

University at Buffalo, United States

Noelly Queiroz Ribeiro,

Federal University of Minas Gerais,

Brazil

*Correspondence:

Carmen Rodríguez-Cerdeira crodcer@uvigo.es;

carmen.rodriguez.cerdeira@sergas.es; carmencerdeira33@gmail.com

Specialty section: This article was submitted to Fungi and Their Interactions,

a section of the journal

Frontiers in Microbiology

Received: 20 March 2020 Accepted: 23 October 2020

Published: 11 November 2020

Citation:

Rodríguez-Cerdeira C, Martínez-Herrera E,

Carnero-Gregorio $M$, López-Barcenas A, Fabbrocini G,

Fida M, El-Samahy M and

González-Cespón JL (2020)

Pathogenesis and Clinical Relevance of Candida Biofilms in Vulvovaginal

Candidiasis.

Front. Microbiol. 11:544480 doi: 10.3389/fmicb.2020.544480

\title{
Pathogenesis and Clinical Relevance of Candida Biofilms in Vulvovaginal Candidiasis
}

\section{Carmen Rodríguez-Cerdeira ${ }^{1,2,3,4 *}$, Erick Martínez-Herrera ${ }^{4,5}$, Miguel Carnero-Gregorio ${ }^{1,6}$, Adriana López-Barcenas ${ }^{3,4,7}$, Gabriella Fabbrocini3,8, Monika Fida ${ }^{3,9}$, May El-Samahy3,10 and José Luís González-Cespón ${ }^{1}$}

'Efficiency, Quality, and Costs in Health Services Research Group (EFISALUD), Health Research Institute, SERGAS-UVIGO, Vigo, Spain, ${ }^{2}$ Department of Dermatology, Hospital do Meixoeiro and University of Vigo, Vigo, Spain, ${ }^{3}$ European Women's Dermatologic and Venereologic Society, Tui, Spain, ${ }^{4}$ Psychodermatology Task Force of the Ibero-Latin American College of Dermatology (CILAD), Buenos Aires, Argentina, ${ }^{5}$ Unidad de Investigación, Hospital Regional de Alta Especialidad de Ixtapaluca, Ixtapaluca, Mexico, ${ }^{6}$ Department of Molecular Diagnosis (Array \& NGS Division), Institute of Cellular and Molecular Studies, Lugo, Spain, ${ }^{7}$ Section of Mycology, Department of Dermatology, Manuel Gea González hospital, Mexico City, Mexico, ${ }^{8}$ Department of Dermatology, University of Naples Federico II, Naples, Italy, ${ }^{9}$ Department of Dermatology, University of Medicine, Tirana, Tirana, Albania, ${ }^{10}$ Department of Dermatology, Faculty of Medicine, Ain Shams University, Cairo, Egypt

The ability of Candida spp. to form biofilms is crucial for its pathogenicity, and thus, it should be considered an important virulence factor in vulvovaginal candidiasis (WV) and recurrent WC (RVVC). Its ability to generate biofilms is multifactorial and is generally believed to depend on the site of infection, species and strain involved, and the microenvironment in which the infection develops. Therefore, both cell surface proteins, such as Hwp1, Als1, and Als2, and the cell wall-related protein, Sun41, play a critical role in the adhesion and virulence of the biofilm. Immunological and pharmacological approaches have identified the NLRP3 inflammasome as a crucial molecular factor contributing to host immunopathology. In this context, we have earlier shown that Candida albicans associated with hyphae-secreted aspartyl proteinases (specifically SAP4-6) contribute to the immunopathology of the disease. Transcriptome profiling has revealed that non-coding transcripts regulate protein synthesis posttranscriptionally, which is important for the growth of Candida spp. Other studies have employed RNA sequencing to identify differences in the 1,245 Candida genes involved in surface and invasive cellular metabolism regulation. In vitro systems allow the simultaneous processing of a large number of samples, making them an ideal screening technique for estimating various physicochemical parameters, testing the activity of antimicrobial agents, and analyzing genes involved in biofilm formation and regulation (in situ) in specific strains. Murine WC models are used to study C. albicans infection, especially in trials of novel treatments and to understand the cause(s) for resistance to conventional therapeutics. This review on the clinical relevance of Candida biofilms in 
WC focuses on important advances in its genomics, transcriptomics, and proteomics. Moreover, recent experiments on the influence of biofilm formation on WC or RVVC pathogenesis in laboratory animals have been discussed. A clear elucidation of one of the pathogenesis mechanisms employed by Candida biofilms in vulvovaginal candidiasis and its applications in clinical practice represents the most significant contribution of this manuscript.

Keywords: vulvovaginal candidiasis, Candida spp., biofilm models, proteomic, genomic, new antiCandida targets

\section{INTRODUCTION}

Vulvovaginal candidiasis (VVC) is a usual fungal infection caused by Candida species, mainly Candida albicans. It is characterized by inflammatory signs and symptoms detected in the vulva and vaginal mucosa that are caused and linked by an overgrowth of Candida species, which are generally present as quiescent vaginal commensals (Sobel, 2007).

The genus Candida belongs to the Saccharomycetaceae family. The organisms reproduce asexually or anamorphically through blastoconidia, do not produce melanin pigments, have diverse morphologies (globose, oval, cylindrical, and elliptical), and are sized between 3 and $10 \mu \mathrm{m}$. In humans, different species of this genus are identified as commensals of the gastrointestinal tract, upper respiratory tract, skin, oral, vulvar, and vaginal mucosa (Neppelenbroek et al., 2014).

Comparative Candida species genomics will enhance our understanding of the genetic and phenotypic variations that occur inside the vulva and vagina and will further facilitate better understanding of the pathogenesis of these commensals in VVC (Bradford et al., 2017).

Despite the fact that $C$. albicans is the most common VVCcausing pathogen, the identification of non-C. albicans Candida (NCAC) species, mainly C. glabrata, as the originator of this infection appears to be continuously increasing. It is difficult to determine its prevalence because the diagnosis and treatment are often based on the symptoms and not dependent on the confirmation by microscopic examination or using culture techniques (Mahmoudi Rad et al., 2011).

Other NCAC species that must be taken into account are C. tropicalis, C. parapsilosis, C. kefyr, C. krusei, C. guilliermondii, C. famata, and C. lusitaniae. The production of virulence factors by these strains depends on the site and degree of invasion, as well as the nature of host response. Early identification of the involved strain is, therefore, essential for rapid diagnosis (Bitew and Abebaw, 2018). The techniques used most frequently for their identification are shown in Figure 1.

Yeasts that are present in the vagina become pathogenic when the host vagina allows it (Miró et al., 2017). Hostrelated factors involve pregnancy (Brown et al., 2019), hormonal imbalance, ill-treated diabetes, immunosuppression (either through immunosuppressive drugs or infection with the human immunodeficiency virus), which can act as a predisposing factor (Yano et al., 2019), use of broad-spectrum antibiotics (Shukla and Sobel, 2019) and glucocorticoids, and genetic predispositions (Gonçalves et al., 2016).

Other less recognized or more debatable factors are oral contraceptive administration (especially when the estrogen dose is high), estrogen therapy, use of intrauterine devices, spermicides, and condoms, and certain hygiene, clothing, and sexual practice-related routines (Corsello et al., 2003; Maraki et al., 2019). In general, the most common clinical characteristic related to vaginal inflammation is itching, which is followed by burning.

Recurrent vulvovaginal candidiasis (RVVC) is featured by four or more episodes of symptomatic infection in the same year, and clearly affects the quality of life in women (Blostein et al., 2017). Djohan et al. (2019) have reported a prevalence of RVVC in 23.5\% (CI95: 19.49-28.02\%) of women of reproductive age and identified five Candida species in a group of 94 patients with RVVC: C. albicans (59.6\%), C. glabrata (19.1\%), C. tropicalis (16\%), C. krusei (4.2\%), and C. inconspicua (1.1\%). However, other authors have provided lower figures, but there is a consensus that the frequency of RVVC is increasing (Gonçalves et al., 2016; Denning et al., 2018).

Among other species, C. kefyr is frequently found to be present in the polyfungal population (Ozcan et al., 2010; Guzel et al., 2011).

However, a new pathogen, C. auris, has emerged recently (Kumar et al., 2015). Another emerging pathogen that has been identified is $C$. nivariensis, which is genetically related to C. glabrata. C. nivariensis was reported for the first time in Canary Islands, Spain, and at present, it seems to widely distributed worldwide. Inhibition of quorum sensing molecules with natamycin against $C$. tropicalis haven been used successfully by researchers (Agustín et al., 2019). However, the number of cases is low possibly due to the impossible phenotypic identification of C. glabrata (Aznar-Marin et al., 2016).

New compounds have been developed, with more candidates in the pipeline, for the treatment of biofilms associated with Candida spp. infections. Some of these are naturally occurring, while others have been developed by synthetic routes optimized in the laboratory. New antifungals such as acridone (de Oliveira et al., 2019) or nanotechnology-based techniques, such as the encapsulation of citric acid into Mg-Al-layered double hydroxides, have shown optimistic trends.

Prebiotics, probiotics, and symbiotics also offer promising results, as these are related to the stimulation of host immunity 


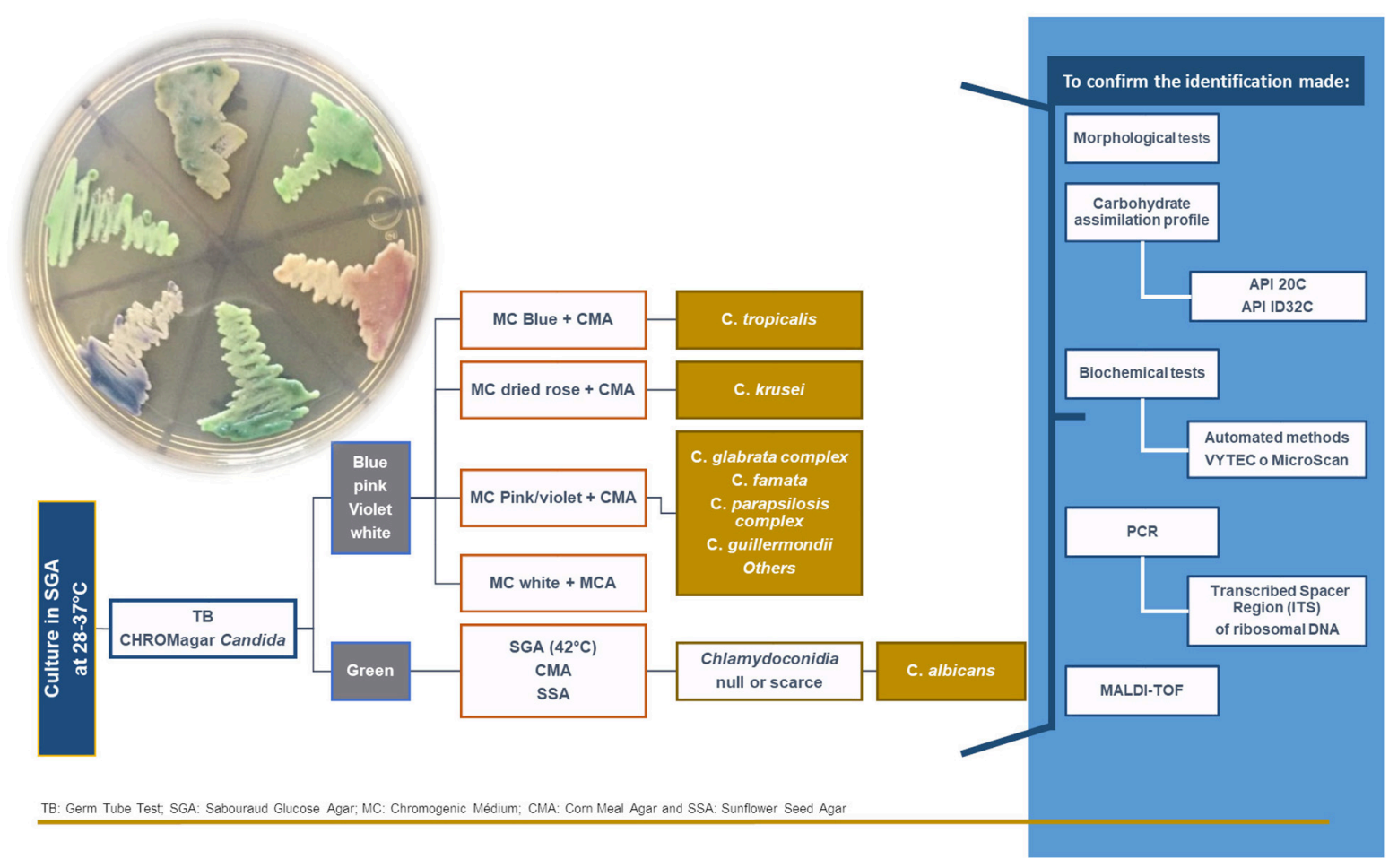

FIGURE 1 | The algorithm used for the identification of Candida yeasts.

and their presence is known to decrease the prevalence of Candida spp. (Davani-Davari et al., 2019).

Plant extracts and essential oils derived from the leaves of plants of Brazilian origin described by Costa et al. (2017), such as Hymenaea courbaril var. courbaril, Myroxylon peruiferum, and Vismia guianensis, have shown therapeutic potential in this regard. The derivatives of flavonoids, such as methylated isoflavones (i.e., formononetin 7-O-apiosyl glucoside) (Martins et al., 2016), or the polyphenol, licochalcone-A, found in the roots of Glycyrrhiza spp. (Seleem et al., 2016) or honey (Fernandes et al., 2020), have also been demonstrated to be useful.

Photodynamic therapy (Ghasemi et al., 2019), quorum sensing molecules and antibodies/peptides (Carrano et al., 2019) have emerged as viable treatment modalities in recent years. More sophisticated techniques, such as lock therapy (Visek et al., 2019), represent an important potential breakthrough in the treatment of biofilms produced due to infection by Candida spp.

In this review, we aimed to discuss the main characteristics of the female vulvovaginal mucosa, and the mechanisms employed by Candida spp. to colonize the host. Furthermore, the different kinds of biofilms formed by Candida spp., their impact on clinical practices, and the development of new agents against them will also be reviewed in depth.

\section{MATERIALS AND METHODS}

The databases MEDLINE (PubMed), and Embase were searched extensively for articles published from January 2003 to January
2020, using the following search terms: vulvovaginal candidiasis, Candida spp., C. albicans, C. glabrata, C. parapsilosis, C. tropicalis, C. kefyr, C. auris, C. nivariensis, biofilm, and antifungal agents. PRISMA Flow Diagram (Figure 2) depicted the flow of reports through the different stages of this systematic review. It mapped the number of records that were identified, included or excluded, and the reasons for exclusions.

\section{CHARACTERISTICS OF THE VULVOVAGINAL MUCOSA AND MECHANISMS THAT Candida spp. DEPLOYS COLONIZE IT}

\section{Vaginal Ecosystem}

The vaginal microbiota, which mainly constitutes of Lactobacillus spp., forms the most important defensive barrier against candidal infections (Smith and Ravel, 2017). The vaginal ecosystem balance is maintained at the expense of articulated interactions of different mechanisms, which keeps the female genital tract (FGT) healthy. Both epithelial cells of the vaginal mucosa and FGT immune system are under the control of the female sex hormones, estradiol, and progesterone. On the vaginal epithelium, estrogens regulate trophism, vascularity, and tissue vitality; in addition, it influences conditions such as humidity, $\mathrm{pH}$, and vaginal discharge as well as vaginal microbiota composition (Achilles et al., 2018). 


\section{PRISMA Flow Diagram}
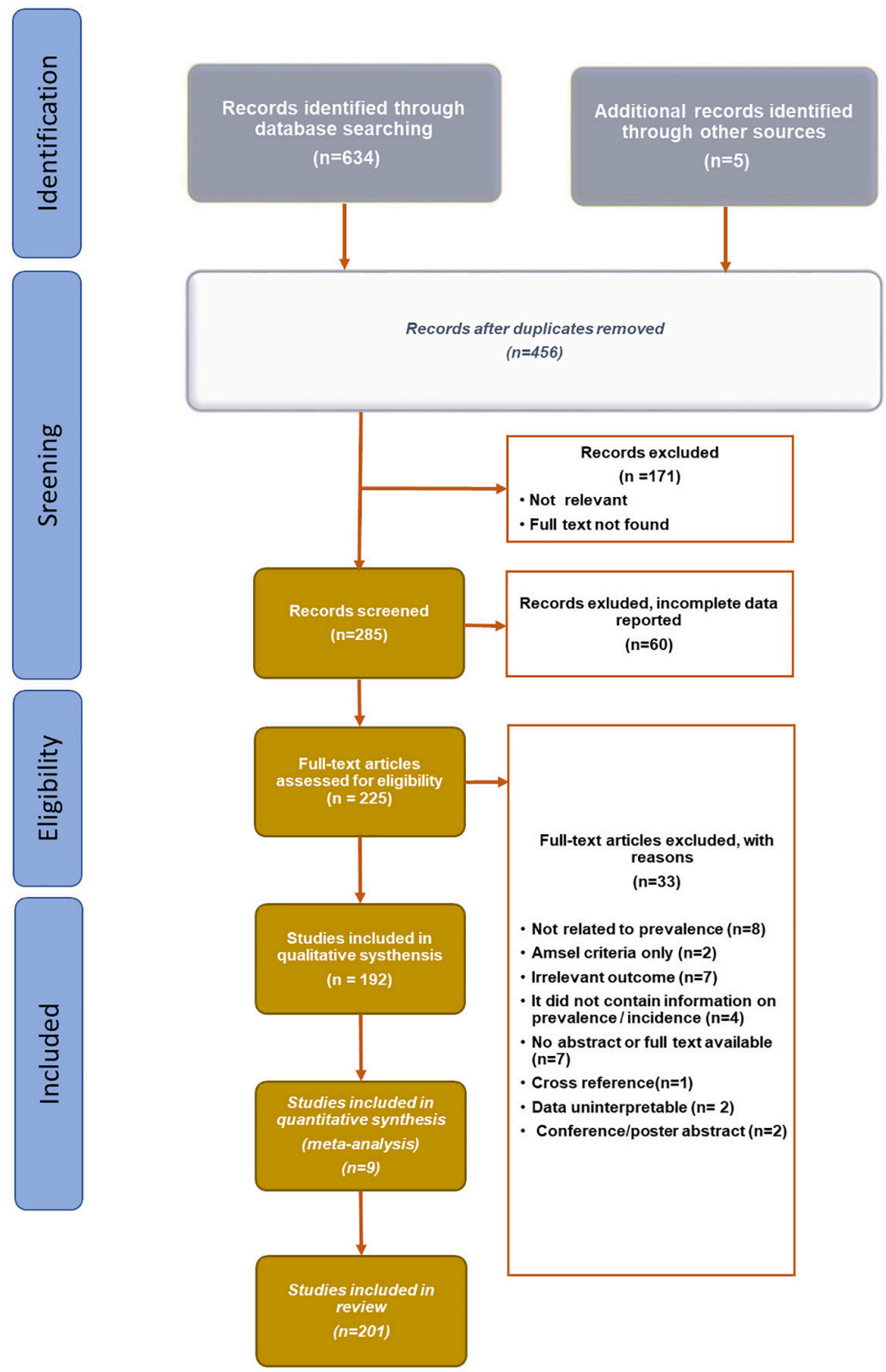

FIGURE 2 | PRISMA Flow diagram (Moher et al., 2015).

Candida spp. is considered as opportunistic pathogens. Although initially it was thought that yeast participates passively in the pathogenesis process and fungal infection establishment, but recently this concept has been modified, proposing an active participation of these microorganisms via the action of virulence factors (El-Houssaini et al., 2019).

Factors contributing to C. albicans pathogenesis include morphogenesis (transition between single-celled yeast cells to filamentous growth forms), secretion of enzymes like aspartyl proteases (SAP) and phospholipases, and host recognition biomolecules (adhesins), which lead to the biofilm formation process. Likewise, the phenotypic change is accompanied by alterations in antigen expression, colonial morphology, and affinity of C. albicans to tissues (El-Houssaini et al., 2019; Monika, 2019).

The experimental information on the contribution of these virulence factors has revealed that their individual participation is not sufficient to explain the mechanisms of damage in the 
host; moreover, there is a combined regulation mechanism operating between them. This was further demonstrated with polymorphism and gene expression analyses of SAPs. The studies currently being carried out on the genetic expression of virulence factors, which depends on different environmental conditions, will allow us to better understand how the biological activity of Candida spp. modifies to favor adhesion or penetration processes and, consequently, modifies its role to become a pathogenic microorganism (Silva et al., 2012; Kalaiarasan et al., 2018; Willems et al., 2018).

Araújo Paulo, de Medeiros et al. (2017) reported that the virulence characteristics of $C$. albicans contributing to its pathogenicity include the skill to adhere to human epithelial and endothelial cells, yeast to hyphae transition, extracellular hydrolytic enzyme (proteinases and phospholipases) secretion, phenotypic adaptability, and biofilm formation. Further, there is a relationship between virulence factor expression and VVC signs and symptoms identified in the patients, but it does not seem to be essential for the transition from colonization to infection.

\section{Adherence}

Adhesion is initiated by non-specific binding, which is based on attractive and repulsive forces that bring the pathogen close to the host surface. Adhesins are biomolecules that promote the binding of specific ligands to host cells. The investigations by Zhao et al. (2003) stake the adhesion about the family of adhesins called ALS (Agglutinin-Like Sequence), which belongs to a group of eight genetically related glycosylated proteins with great allelic variability (ALS1-ALS7 and ALS9). ALS1 and ALS3 are particularly found to be important in the adhesion process. Other molecules that also promote the adhesion and penetration of $C$. albicans into the tissues are the polysaccharides, proteins, and lipids present on cell surface. Data supplied by the C. albicans genome sequencing project provided the main indication that the strain SC5314 encodes two different ALS9-like sequences and three ALS genes (ALS5, ALS1, and ALS9) next to chromosome 6 (Araújo et al., 2017).

Wilkins et al. (2018) showed that the eukaryotic proteome contains certain components that are encoded by open reading frame (ORF)s possessing protein-coding tandem repeat (TRs) (TR-ORFs, pcTRs), but their biological consequences are not clearly known. Ichikawa et al. (2019) analyzed the adherence and cytotoxicity of C. glabrata that selectively adhered to the epithelial cells. On the contrary, C. parapsilosis showed poor adherence to the HaCaT keratinocytes. C. glabrata caused more damage to the A549 cells than to the HaCaT cells, suggesting that Candida spp. exhibits different effects depending on the tissue on which they can adhere.

Modrzewska and Kurnatowski (2015) demonstrated that the adherence of Candida spp. on the tissue or cell wall of a host is based on the relationship that might exist between the two. A variety of genes that are responsible for the adhesion capacity of fungal cell wall, like HWP1, which encodes protein 1 of the hyphal wall and germ tubes and is responsible for biofilm formation. It is also responsible for the fungal virulence capacity and therefore, provides resistance to antifungal agents. This gene is identified in both oral cavity and vaginal yeast infections (Fan et al., 2013).

Ardehali et al. (2019) identified that the frequency of HWP1 gene among C. albicans was 95\%, with HWP1 being the most detected virulence factor, and SAP4 being the least detected one in the clinical specimens collected from patients hospitalized in the Intensive Care Unit (ICU) of Milad hospital, Tehran, Iran.

According to Cota and Hoyer (2015), the ALS genes encode fungal glycoproteins on the cell surface. A total of eight ALS genes have been reported so far (ASL1-7 and ALS9). According to Liu and Filler (2011), the ALS3 gene exhibits a dual function of adhesin and invasion. ALS3 is used for the preparation of vaccines because of its level of in vivo dispersion. According to Zajac et al. (2016), other genes that have been involved in cell adhesion are EPA (epithelial adhesin) genes that are specifically identified in C. glabrata, as in this Candida sp., ALS genes have not been identified to date.

According to Modrzewska and Kurnatowski (2015), the most important adhesins present on the fungal cell wall in Candida spp. are: ALS, EPA, HWP1, but also EAP1, SUN41, CSH1 and probably HYR1; for significant adhesion, they also possess Sap (secreted aspartyl proteases). Various other genes reported to positively affect adhesion and hyphal formation are CZF1, EFG1, TUP1, TPK1, TPK2, HGC1, RAS1, RIM101, VPS11, ECM1, CKA2, BCR1, BUD2, RSR1, IRS4, CHS2, SCS7, UBI4, UME6, TEC1, and GAT2.

\section{Morphogenesis}

Morphogenesis refers to the conversion of a particular yeast form (unicellular) to the filamentous form of the fungus (hypha or pseudohypha), making it possible to adapt to different biological niches, which favors the fungal spread.

According to Min et al. (2019), N-acetylglucosamine (GlcNAc) potently induces the transition of $C$. albicans from budding to filamentous hypha growth. It also stimulates an epigenetic change that converts the white cells to opaque cells, which vary in morphology, metabolism, and virulence properties.

According to Min et al. (2018), the presence of TF (transcription factor) Ndt80 is necessary for the growth of hyphae in C. albicans and its presence is significant since it is conserved in most of the fungal species; however, it must be taken into account that its quantity is variable among the different fungal species. It regulates a variety of processes, such as sexual development, resistance to antifungals, fibrillation, virulence, and nutritional stress response, among others.

The human fungal pathogen $C$. albicans contains three virulence genes, namely NDT80, REP1, and RON1. RON1 deletion leads to growth defects when grown in GlcNAc media and hypha induction. To avoid this, a new short cross-linked palindromic/CRISPR repeat associated with Cas9 has been used for gene deletions (Min et al., 2019).

\section{Phenotypic Switch}

Tang et al. (2019) demonstrated that the majority of C. albicans strains are capable of undergoing the phenomenon of phenotypic switch, which is associated with the manifestation of phenotypic changes at high frequency and a consequence of the action 
of numerous environmental factors. This phenomenon induces an epigenetic change in colonial morphology. Hu et al. (2016) collected and subsequently employed 231 clinical isolates for genotyping as well as phenotypic switch analysis. A total of 65 different genotypes were recognized by microsatellite locus (CAI) genotyping assay, and some prominent genotypes were identified from certain human niches. The authors established that there is an association between the phenotypic switching and genotypes of the CAI microsatellite locus in these C. albicans clinical isolates.

During this process, enzymes able to break down the structural polymers that provide accessible nutrients for fungal growth, capability to evade the immune system, and suppress the host pro-inflammatory response are released. They are also responsible for inactivating certain molecules that are directly linked to the host defense mechanisms (Hu et al., 2016). The main extracellular enzymes (Basmaciyan et al., 2019) that are related to the pathogenesis of Candida spp. are described below:

Secreted aspartic proteinases (Sap) (Kadry et al., 2018) are regarded as one of the most critical virulence factors as they are related to adhesion, invasion, tissue damage, and evasion of the host immune system, due to its ability to hydrolyze various host proteins, including albumin, keratin, collagen, fibronectin, interleukin $1 \beta$ (IL-1 $\beta$ ), and Immunoglobulin A.

\section{Phospholipases}

Studies by Richmond and Smith (2011) and Dabiri et al. (2018) demonstrated the existence of glycoproteins with hydrolase activity (glyphospholipid esters are hydrolyzed) and lysophospholipase transacylase (release fatty acids from lysophospholipids and transfer free fatty acid to another phospholipid), which play key roles in the infection process.

\section{BIOFILMS}

For a long time, investigations in the area of microbial biofilms have received increasing momentum and scientific evidence has led to a change in the way we consider microbial life (de Barros et al., 2020). Biofilms are defined as heterogeneous and dynamic microbial communities undergoing continuous transformation. They can be comprised by a single bacterial/fungal species, or can be polymicrobial. Since there are differences between biofilms formed on mucosal and abiotic cells, it is precise to have in vitro and in vivo models that can mimic these processes (Tournu and Van Dijck, 2012).

In this context, new tools to analyze Candida biofilms have been implemented, including genomic, transcriptomic, proteomic, and metabolomics approaches, using a wide variety of animal models.

According to Cavalheiro and Teixeira (2018), biofilm formation is a complicated process, which starts with adhesion on an abiotic surface, a tissue, or the air-liquid interface. It is a continuous process, which undergoes different stages of development: (a) conditioning, (b) adhesion, (c) quorum sensing-induced extracellular matrix synthesis, (d) maturation, and (e) dispersion.
These phases lead to the formation of a uniform structure in the form of homogeneous deposits and cellular viscous accumulations surrounded by a matrix of polymers with open channels for water movement (Chandra and Mukherjee, 2015).

Cells in the biofilms have different properties than those of isolated cells, which is because they have low growth rates and great resistance to antimicrobial treatment, and it makes their behavior different from those of planktonic cells (Muzny and Schwebke, 2015). Biofilms are biological systems that interact and evolve together. Hence, they need a wide network of genetic regulation to carry out both intra- and inter-cellular communication and specialization and originate biofilms made up of the same species or multi-species (Rodríguez-Cerdeira et al., 2019). C. albicans biofilm formation is a complex process that begins when the yeast cells adhere to host tissue surface, and the biofilm starts to form at an early stage (8-11 h), undergoes an intermediate stage (12-30 h), and finally reaches the mature stage (38-72 h) (Mathé and Van Dijck, 2013).

The mature biofilm comprises a dense network of yeasts, hyphae, and pseudohyphae, which is covered by an extracellular matrix and frequently associated with bacteria, as also described by Silva et al. (2012, 2014). Each Candida species (C. albicans, C. glabrata, C. parapsilosis, C. tropicalis, C. nivariensis, C. kefyr, and C. auris) shows significant peculiarities in terms of biofilm formation, which results in different morphologies, extracellular matrix composition, and resilience to antifungal agents (Cavalheiro and Teixeira, 2018) (Figure 3).

The importance of certain virulence factors was found to be closely related to Sap, which is related to biofilm production as described by Kadry et al. (2018). Isolates that were found to be resistant to three different anti-fungal drugs were reported as strong biofilm producers and shown to possess proteolytic activity as they contained either Sap9 or Sap10, or both (Černáková et al., 2019).

El-Houssaini et al. (2019) identified the virulence factors related to hydrolases, which are involved in cell surface hydrophobicity and biofilm production in vaginal samples. C. albicans resistance and virulence patterns observed in the samples were variable. The samples were highly resistant to physical and chemical treatments, making it difficult to treat them (Marak and Dhanashree, 2018).

\section{Genomics of the Biofilm}

Numerous genes involved in biofilm formation have been identified in the C. albicans genome, including 50 transcriptional regulatory genes, and 101 transcriptional non-regulatory genes (Shukla and Sobel, 2019). Nobile et al. (2012) described the six main transcriptional regulatory genes known as "master" transcriptional regulators, including Efg1 (enhanced filamentous growth), Tec1 (transposon enhancement control), Bcr1 (biofilm and cell wall regulator), Ntd80 (meiosis-specific transcription factor), Brg1 (biofilm regulator), and Rob1 (biofilm regulator). Each of these genes are mandatory for normal biofilm development and have been identified both in vitro, under standard laboratory conditions and in vivo, in laboratory animals (rats). 


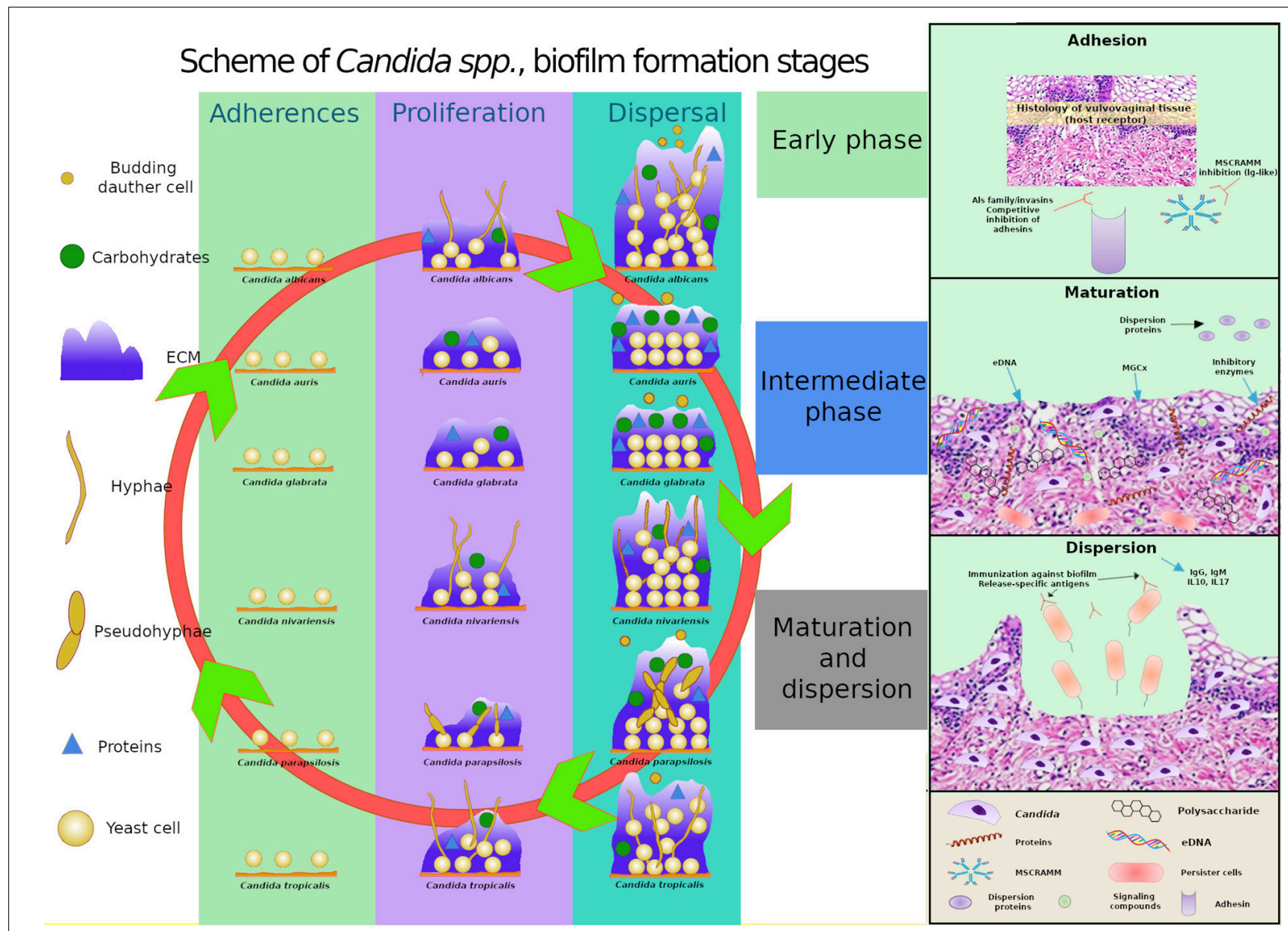

FIGURE 3 | Comparative schematics of three stages of biofilm formation in C. albicans, C. glabrata, C. tropicalis, and C. parapsilosis, C. auris and C. nivariensis highlighting the different capacities of the species in producing extracellular matrix (ECM), the varying components present in the ECM, and the ability of the species to exhibit different cell morphologies, and highlights of the transcriptional factors involved in adhesion, extracellular polymeric substances, filamentation, and biofilm formation. MSCRAMM, microbial surface components recognizing adhesive matrix molecules; MGCx, extracellular matrix mannan-glucan complex; eDNA, external DNA.

Apart from these 6 genes, 44 other transcriptional regulatory genes have also been identified, and the deletion of these genes has been associated with erroneous biofilm formation ( $\mathrm{Ni}$ et al., 2009). Chatterjee et al. (2015) identified eight OPT genes encoding the oligopeptide transporters that help C. auris to adapt to different host tissues. They also found orthologs for these genes that were believed to carry hexose, maltose, and permeases (amino acid permeases, sulfur permeases, allantoic permeases, glycerol permeases, and iron permeases), which also help the fungi to adapt and live in their host. Other transcriptional regulators have also been recently found to be involved in adherence (Finkel et al., 2012).

The first step in biofilm formation process is surface adhesion, in which the Candida cell wall interacts with the host cell surfaces. This process involves a series of genes that encode several proteins, such as ALS adhesins, of which ALS1, ALS3, and ALS5 are implicated in the adhesion process; Eap1, regulated by the factor EFG1; HWP1, which promotes the fixation of Candida cells to the host surface and is a potential pathogenicity factor (it is absent in C. glabrata); PGA10 and PBR1-it has been shown that when the PBR1 gene is deleted, the adhesion of C. albicans to blood cells decreases; EPA family of genes, of which EPA1, EPA6, and EPA7 are the main epithelial adhesins, and their deletion hinders or decreases adhesion to surfaces; AWP adhesins, whose expression is higher in biofilms than in plant cells (Orsi et al., 2014; Valotteau et al., 2019).

Inglis and Sherlock (2013) showed that the expression of these wall proteins is regulated by two main genes: BCR1 and TEC1. TEC1 regulates BCR1 via cell signaling cascades and is involved in yeast differentiation into hypha. EPAs (epithelial adhesin) are specific for C. glabrata and the genes encoding ALS proteins have not been observed in mucosa yet.

CKA2, BCR1, BUD2, RSR1, and HWP1 are the genes that modify adhesion and tissue damage, but not invasion, in the host. Other genes that positively affect adhesion and hyphal formation have been reported, including CHS2 (synthesizes 
chitin), SCS7 (involved in cell membrane sphingolipid formation), UBI4 (contributes to ubiquitination), and genes that participate in adhesion and filamentation. UME6, TEC1, and GAT2 are involved in subsequent biofilm formation (Modrzewska and Kurnatowski, 2015).

The importance of the adherence regulatory genes (Bcr1, Ace2, and Snf5) lies in the fact that they are necessary for biofilm formation in vitro (Guan et al., 2013; van Wijlick et al., 2016; Burgain et al.; 2019).

After the initial adhesion of round yeast cells to the host surface to form a basal layer, the next phase of biofilm establishment is the growth and proliferation of hyphal cells. During the $C$. albicans proliferation phase, it multiplies and forms a monolayer adhesion zone where filamentation occurs, with the hyphae leading to general stability and acting as a support for the different cell morphologies: yeast, pseudohypha, hypha, and other cells of microorganisms that might be a part of the biofilm (Chandra and Mukherjee, 2015). According to McCall et al. (2018) and Min et al. (2018), hyphal growth in $C$. albicans is dependent on the presence of TF (transcription factor) Ndt80, which is responsible for regulating a variety of processes, including sexual development, resistance to antifungals, fibrillation, virulence, and nutritional stress response, among others. Hence, C. albicans possesses three paralogs (genes of different species, which descends to a single gene by genetic duplication in evolution) of NDT80 (NDT80, RON1, and REP1), and each of them provides C. albicans with specific characteristics. NDT80 is involved in resistance under different stress conditions, as well as in hyphal growth, and RON1 deletion has shown to cause growth defects when C. albicans is grown in GlcNAc media.

Glazier et al. (2017) highlighted that biofilm maturation is regulated by several transcription factors in C. albicans, including BCR1, EFG1, TEC1, NDT80, ROB1, and BRG1. When any one of them is deleted, biofilms are not formed correctly. Other transcription factors, such as CZF1, GZF3, UME6, CPH2, and ACE2, are also shown to be involved in C. parapsilosis biofilm formation. Biofilm formation decreases dramatically if ACE2 is deleted, and it also regulates biofilm development in C. albicans; however, in C. glabrata, the ability to cause disease is increased when ACE2 is inactive.

$\mathrm{Ng}$ and Dean (2017) reported that the increased expression and maturation of sgRNA facilitates and improves the CRISPR/Cas9 mutagenesis in C. albicans by about 10 times. This may help us edit the C. albicans genome. Finally, REP1 has been shown to be negatively involved in the expression of the MDR1 drug flow pump, which provides resistance against several microorganisms (Chen et al., 2009).

In the maturation phase, biofilm development continues via morphological modifications, an increase in the number of cells, and extracellular polysaccharide matrix production. This extracellular matrix mediates adhesive and cohesive interactions, grants mechanical stability and integrity, allows cell dispersion, limits the diffusion of toxic substances and nutrients, and even acts as an enzyme system. However, the main function of the extracellular matrix is to protect the biofilm from the important clinical repercussions, acting as a physical barrier to protect the biofilm cells from environmental factors (Chandra and Mukherjee, 2015; Rodríguez-Cerdeira et al., 2019).

Apart from the composition of the matrix, several recent studies have focused on its genetic regulation. C. albicans biofilm matrix in vivo and in vitro models were biochemically analyzed by Flemming and Wingender (2010) to identify the macromolecular components. The composition was as follows: $55 \%$ proteins and their glycosylated counterparts, $25 \%$ carbohydrates, $15 \%$ lipids, and 5\% non-coding DNA. $\alpha$-1,2-branched $\alpha$-1,6-mannans were the most frequent polysaccharides related to unbranched $\alpha$-1,6-glucans, forming a mannan-glucan complex on the matrix. However, they were a smaller proportion of extracellular matrix (ECM) components in C. albicans than $\beta$-1,3-glucan and $\beta$-1,6-glucan (Zarnowski et al., 2014).

Mitchell et al. (2015) and Dominguez et al. (2018) highlighted the importance of mannan and $\beta$-1,6-glucan in ECM formation. The elimination of proteins involved in ECM formation by deleting any one of the seven genes that governs the level of matrix mannan and $\beta$-1,6-glucan (ALG11, MNN9, MNN11, VAN1, MNN4-4, PMR1, and VRG4 for mannan production; BIG1 and KRE5 for $\beta$-1,6-glucan production) resulted in complete disappearance of the biofilm. In C. parapsilosis, the main function of Efg1 is to behave as a regulatory switch and participate in biofilm formation. Its absence leads to the production of an incomplete biofilm (Connolly et al., 2013).

In C. albicans, Cph1 acts as the terminal transcription factor of the MAP kinase pathway (Freire et al., 2018). This protein belongs to the family of the STE type transcription factor, which is also present in other Candida spp. (Bandara et al., 2013).

Brg1 controls the growth of hyphae in $C$ albicans. When it is overexpressed, there is an increase in the expression of hyphaespecific genes, along with ALS3, HWP1, and ECE1 (Su et al., 2018). In C. parapsilosis, a homolog of Brg1 has been identified (Holland et al., 2014). According to Mendelsohn et al. (2017), the transcription factor Ume6, together with Nrg1 and Rfg1 decreases the expression of hypha specific genes ALS3, ECE1, and HWP1 in both C. albicans and C. tropicalis.

The cell surface proteins encoded by HYR1, ECE1, RBT5, ECM331, HWP1, ALS3, ALS1, and ALS9 genes are all regulated by Bcr1 gene. Upon overexpression of ALS3 in a bcr1/bcr1 cell, the biofilm formation phenotype was shown to be completely restored (Freire et al., 2018).

Vandeputte et al. (2012) identified that Rcal/Cst6 in C. albicans regulates hypha formation by facilitating the expression of GWP1, ECE1, HGC1, and ALS3 genes and the transcription factor Efg1. Cst6 is also a transcriptional controller of biofilm growth. It is a bZIP transcription factor, which belongs to the ATF/CREB family that inhibits the expression of the EPA6 gene and encodes an adhesion protein in the C. glabrata biofilm (Pohlers et al., 2017).

In C. glabrata, Leiva-Peláez et al. (2018) demonstrated that the expression of several related genes is subjected to subtelomeric silencing. HYR1, EPA1, EPA2, EPA3, EPA4, EPA5, EPA6, and EPA7 genes of C. glabrata undergo subtelomeric silencing due to their loci proximity to a telomere. The Sir complex (Sir2-Sir4), 
Rap1, Rif1, yKu70, and yKu80, as well as the Swi/Snf complex are shown to be involved in regulating biofilm formation.

Deletion of the PMR1, KRE5, and FKS1 genes was associated with the increased susceptibility to fluconazole (Navarro-Arias et al., 2016; Tanaka et al., 2016; Jiang et al., 2018). Chowdhary et al. (2018) demonstrated that persistent cells cultured from the biofilm exhibit higher expression of CDR genes (Khosravi Rad et al., 2016). According to Feng et al. (2016), a set of isogenic C. albicans strains carrying single or double deletions in genes encoding efflux pumps $(\Delta \mathrm{cdr} 1, \Delta \mathrm{cdr} 2, \Delta \mathrm{mdr} 1 / \mathrm{drc} 2$, and $\Delta \mathrm{mdr} 1 / \mathrm{cdr} 1)$ show antifungal resistance with paired strains. Tan et al. (2018) demonstrated that $\beta$-1,3-glucan has a crucial role in Candida biofilm formation and stress response in biofilmforming Candida. They also showed that $\beta$-1,3-glucanase might be useful as an anti-biofilm agent.

In contrast, there are two major regulators of ECM production: Rml1 and Zap1. It has been shown that Rm11 deletion leads to the reduction in matrix levels (Nett et al., 2011; Pierce et al., 2017). However, Zap1 deletion leads to an increase in matrix levels, which is due to the overexpression of the glucoamylases, Gca1 and Gca2, as these enzymes, together with other hydrolyzing enzymes, are important for biopolymer degradation (Gulati and Nobile, 2016). Previous studies revealed that $\Delta$ zap1 mutant, which is defective in the expression of zinc regulator Zap1, enhances the accumulation of yeast cells in biofilms (Ganguly et al., 2011).

In the late or dispersal phase, unbound Candida cells scatter from the biofilm and attempt to colonize other surfaces. Thus, it is possible for the cells to initiate the formation of new biofilms or spread in the host tissues, which ultimately leads to the development of candidemia and disseminated invasive diseases. Dispersed cells exhibit strong adherence, capacity to form new biofilms, and virulence. This process depends on three identified transcriptional regulators: Pes1, Nrg1, and Ume6. The transcriptional regulators, $\mathrm{Nrg} 1$ and Ume6, are of significant importance as their overexpression is shown to increase the number of sprawling cells actively released from the biofilm (Araújo et al., 2017).

In the biofilm maturation phase, ECM production is also extremely important. The gene responsible for glucan synthesis is FKS1, which is involved in resistance to fluconazole in C. albicans and promotes biofilm maturation in the presence of high glucose levels in C. parapsilosis. RLM1 and ZAP1 are the other two regulatory genes involved in matrix formation in C. albicans. Some ZAP1 target genes are CSH1 and IFD6 (negative regulators), and GCA1, GCA2, and ADH5 (positive regulators) that are associated with $\beta$-1,3-glucan production from the biofilm matrix. RML1 is a positive regulator, and its deletion reduces the matrix levels significantly. Other glucan regulatory genes associated with matrix formation are BGL2, PHR1, XOG1, CCR4, GAS1, GAS2, and GAS5 (Araújo et al., 2017).

The last step in biofilm formation is the detachment and dispersion of cells or parts of the biofilm, which further get displaced and colonize other parts of the host. The lack of nutrients or changes in the environment can favor this phase, which then leads to the development of infection in other organs. For this step, there are three genes involved: PES1, UME6 and
NRG1. NRG1 is a negative regulator of filamentation and UME6 is necessary for the extension of hyphae (Beitelshees et al., 2018).

The main genes implicated in the genetic control of biofilm formation in Candida spp. are collated in Table 1.

\section{Proteomics of the Biofilms}

Biofilm associated proteins (55\% of the biofilm dry weight) are mainly glycoproteins, glycolytic enzymes, and heat shock proteins. Around 565 different proteins have been identified, representing a total of 458 different biochemical activities (Thomas et al., 2006). Many of them are categorized as secretion signals, but most of these proteins do not have any such signal, indicating a non-canonical secretion pathway and/or protein increment occurring after cell death. In addition, host proteins including proteins related to the heme group and inflammatory and leukocyte-associated proteins, like hemoglobin, myeloperoxidase, C-reactive protein, and alarmin S100-A9 have also been found in vivo (Nett et al., 2015).

According to Hirota et al. (2017), the extracellular matrix of C. albicans is composed of extracellular DNA (eDNA), which has a crucial role in Candida biofilm formation and its structural integrity, and promotes the morphological transition from yeast to hyphal growth form during C. albicans biofilm development. The eDNA is mostly made up of random non-coding sequences and might also have an important role in antifungal resistance.

The adhesins of the fungal wall are modular proteins, and their precursors possess signal peptides to enter in the ER and GPI anchors. The mature proteins possess an $\mathrm{N}$-terminal domain, which generally determines the ligand binding specificity of adhesins and is followed by a low complexity domain that in most cases contains internal tandem repeats. These internal tandem repeats have an important role in the adhesion of the fungal cells and exposure of the ligand-binding domains, which is modulated by the number of repeated copies, and consequently by the size variations of the adhesin-encoding genes identified in the clinical isolates (Willaert, 2018). According to Wagener et al. (2012), there are numerous phenotypic variations between the clinical isolates of C. glabrata in their ability to adhere to the abiotic surfaces for medical importance.

As high expression of heat shock proteins encourages Candida yeast-hyphae switch, which is an essential step in biofilm development, the expression of Hsp genes during C. albicans biofilm formation has been investigated previously (Becherelli et al., 2013). In contrast, heat shock protein 90 (Hsp 90) has also been shown to be involved in the dispersion process. The overexpression of the same leads to a decrease in the number of dispersed cells that are released and induction of the filamentation process. The authors recognized 226 C. albicans Hsp90 genetic interactors under planktonic conditions, of which 56 were identified to be implicated in transcriptional regulation. Six of these transcriptional regulators have previously been involved in biofilm development, proposing that the genetic interactors of $\mathrm{Hsp} 90$ found in planktonic conditions might have functional significance in biofilm formation. They further studied the relationship between Hsp90 and five of these transcription factor genetic interactors: BCR1, MIG1, TEC1, TUP1, and UPC2 (Diezmann et al., 2015). 
TABLE 1 | The main genes involved in biofilm formation in Candida spp.

\begin{tabular}{|c|c|c|}
\hline Type & Gene & References \\
\hline \multirow[t]{34}{*}{ Adhesion } & ALS1 & $\begin{array}{l}\text { Finkel et al., 2012; Holland et al., } \\
2014\end{array}$ \\
\hline & ALS3 & $\begin{array}{l}\text { Finkel et al., 2012; Holland et al., } \\
\text { 2014; Mendelsohn et al., 2017; } \\
\text { Freire et al., 2018; Su et al., } 2018\end{array}$ \\
\hline & ALS5 & Finkel et al., 2012 \\
\hline & ASL9 & Holland et al., 2014 \\
\hline & AWP & Finkel et al., 2012 \\
\hline & BCR1 & $\begin{array}{l}\text { Guan et al., 2013; Inglis and } \\
\text { Sherlock, 2013; Holland et al., } \\
\text { 2014; Orsi et al., 2014; } \\
\text { Modrzewska and Kurnatowski, } \\
\text { 2015; Marak and Dhanashree, } \\
\text { 2018; Burgain et al., 2019; } \\
\text { Valotteau et al., } 2019\end{array}$ \\
\hline & BUD2 & Valotteau et al., 2019 \\
\hline & $\mathrm{CHS} 2$ & Valotteau et al., 2019 \\
\hline & CKA2 & Valotteau et al., 2019 \\
\hline & $\mathrm{CSH} 1$ & Gulati and Nobile, 2016 \\
\hline & CZF1 & Burgain et al., 2019 \\
\hline & EAP1 & Finkel et al., 2012 \\
\hline & ECE1 & $\begin{array}{l}\text { Holland et al., 2014; Mendelsohn } \\
\text { et al., 2017; Freire et al., 2018; } \\
\text { Su et al., } 2018\end{array}$ \\
\hline & ECM1 & Orsi et al., 2014 \\
\hline & ECM331 & Holland et al., 2014 \\
\hline & EFG1 & $\begin{array}{l}\text { Orsi et al., 2014; Mitchell et al., } \\
\text { 2015; Mendelsohn et al., 2017; } \\
\text { Dominguez et al., 2018; Marak } \\
\text { and Dhanashree, 2018; Burgain } \\
\text { et al., } 2019\end{array}$ \\
\hline & EPA1 & $\begin{array}{l}\text { Finkel et al., 2012; Vandeputte } \\
\text { et al., } 2012\end{array}$ \\
\hline & EPA2 & Vandeputte et al., 2012 \\
\hline & EPA3 & Vandeputte et al., 2012 \\
\hline & EPA4 & Vandeputte et al., 2012 \\
\hline & EPA5 & Vandeputte et al., 2012 \\
\hline & EPA6 & $\begin{array}{l}\text { Finkel et al., 2012; Freire et al., } \\
2018\end{array}$ \\
\hline & EPA7 & $\begin{array}{l}\text { Finkel et al., 2012; Vandeputte } \\
\text { et al., } 2012\end{array}$ \\
\hline & GAT2 & Valotteau et al., 2019 \\
\hline & HGC1 & Mendelsohn et al., 2017 \\
\hline & HWP1 & $\begin{array}{l}\text { Finkel et al., 2012; Holland et al., } \\
\text { 2014; Freire et al., 2018; Su } \\
\text { et al., 2018; Valotteau et al., } 2019\end{array}$ \\
\hline & HYR1 & $\begin{array}{l}\text { Vandeputte et al., 2012; Holland } \\
\text { et al., } 2014\end{array}$ \\
\hline & PBR1 & Finkel et al., 2012 \\
\hline & PGA10 & Finkel et al., 2012 \\
\hline & RBT5 & Holland et al., 2014 \\
\hline & RSR1 & Valotteau et al., 2019 \\
\hline & SCS7 & Valotteau et al., 2019 \\
\hline & SNF5 & $\begin{array}{l}\text { Inglis and Sherlock, 2013; } \\
\text { Modrzewska and Kurnatowski, } \\
\text { 2015; van Wijlick et al., } 2016\end{array}$ \\
\hline & TEC1 & Valotteau et al., 2019 \\
\hline
\end{tabular}

(Continued)
TABLE 1 | Continued

\begin{tabular}{|c|c|c|}
\hline Type & Gene & References \\
\hline & UB|4 & Valotteau et al., 2019 \\
\hline & UME6 & $\begin{array}{l}\text { Ganguly et al., 2011; Gulati and } \\
\text { Nobile, 2016; Su et al., 2018; } \\
\text { Burgain et al., 2019; Valotteau } \\
\text { et al., } 2019\end{array}$ \\
\hline \multirow[t]{21}{*}{ Biofilm formation } & ADH5 & Gulati and Nobile, 2016 \\
\hline & ALG11 & Mitchell et al., 2015 \\
\hline & BIG1 & Mitchell et al., 2015 \\
\hline & FKS1 & $\begin{array}{l}\text { Gulati and Nobile, 2016; } \\
\text { Navarro-Arias et al., 2016; Jiang } \\
\text { et al., 2018; Leiva-Peláez et al., } \\
2018\end{array}$ \\
\hline & GCA1 & $\begin{array}{l}\text { Nett et al., 2011; Gulati and } \\
\text { Nobile, } 2016\end{array}$ \\
\hline & GCA2 & $\begin{array}{l}\text { Nett et al., 2011; Gulati and } \\
\text { Nobile, } 2016\end{array}$ \\
\hline & IFD6 & Gulati and Nobile, 2016 \\
\hline & KRE5 & $\begin{array}{l}\text { Mitchell et al., 2015; } \\
\text { Navarro-Arias et al., 2016; Jiang } \\
\text { et al., 2018; Leiva-Peláez et al., } \\
2018\end{array}$ \\
\hline & MNN11 & Mitchell et al., 2015 \\
\hline & MNN4-4 & Mitchell et al., 2015 \\
\hline & MNN9 & Mitchell et al., 2015 \\
\hline & PMR1 & $\begin{array}{l}\text { Mitchell et al., 2015; } \\
\text { Navarro-Arias et al., 2016; Jiang } \\
\text { et al., 2018; Leiva-Peláez et al., } \\
2018\end{array}$ \\
\hline & RAP1 & Vandeputte et al., 2012 \\
\hline & RIF1 & Vandeputte et al., 2012 \\
\hline & RM11 & $\begin{array}{l}\text { Feng et al., 2016; Tan et al., } \\
2017\end{array}$ \\
\hline & SIR Complex & Vandeputte et al., 2012 \\
\hline & SWI/SNF & Vandeputte et al., 2012 \\
\hline & VAN1 & Mitchell et al., 2015 \\
\hline & VRG4 & Mitchell et al., 2015 \\
\hline & YKU70 & Vandeputte et al., 2012 \\
\hline & YKU80 & Vandeputte et al., 2012 \\
\hline \multirow[t]{3}{*}{ Morphogenesis } & NTD80 & $\begin{array}{l}\text { van Wijlick et al., 2016; Marak } \\
\text { and Dhanashree, 2018; Min } \\
\text { et al., 2018; Burgain et al., } 2019\end{array}$ \\
\hline & REP1 & $\begin{array}{l}\text { Glazier et al., 2017; Min et al., } \\
2018\end{array}$ \\
\hline & RON1 & Min et al., 2018 \\
\hline $\begin{array}{l}\text { Oligopeptide } \\
\text { transporter genes }\end{array}$ & OPT & Ni et al., 2009 \\
\hline \multirow[t]{4}{*}{ Resistance } & CDR1 & $\begin{array}{l}\text { Pohlers et al., 2017; Chowdhary } \\
\text { et al., } 2018\end{array}$ \\
\hline & CDR2 & $\begin{array}{l}\text { Pohlers et al., 2017; Chowdhary } \\
\text { et al., } 2018\end{array}$ \\
\hline & MDR1 & Glazier et al., 2017 \\
\hline & TPO1_2 & Pohlers et al., 2017 \\
\hline \multirow[t]{2}{*}{$\begin{array}{l}\text { Transcriptional } \\
\text { regulatory genes }\end{array}$} & ACE2 & $\begin{array}{l}\text { Guan et al., 2013; Inglis and } \\
\text { Sherlock, 2013; Modrzewska } \\
\text { and Kurnatowski, 2015; Burgain } \\
\text { et al., } 2019\end{array}$ \\
\hline & BGL2 & Gulati and Nobile, 2016 \\
\hline
\end{tabular}

(Continued) 
TABLE 1 | Continued

\begin{tabular}{ll}
\hline Type & References \\
\hline BRG1 & Bandara et al., 2013; Freire \\
& et al., 2018; Marak and \\
& Dhanashree, 2018; Burgain \\
& et al., 2019 \\
& Gulati and Nobile, 2016 \\
CCR4 & Connolly et al., 2013; Yano \\
CPH1 & et al., 2019 \\
& Burgain et al., 2019 \\
CPH2 & Mendelsohn et al., 2017; Freire \\
CST6 & et al., 2018 \\
& Gulati and Nobile, 2016 \\
GAS1 & Gulati and Nobile, 2016 \\
GAS2 & Gulati and Nobile, 2016 \\
GAS5 & Mendelsohn et al., 2017 \\
GWP1 & Burgain et al., 2019 \\
GZF3 & Ganguly et al., 2011; Gulati and \\
NRG1 & Nobile, 2016; Su et al., 2018 \\
& Ganguly et al., 2011; Gulati and \\
PES1 & Nobile, 2016 \\
& Gulati and Nobile, 2016 \\
PHR1 & Mendelsohn et al., 2017 \\
RCA1 & Su et al., 2018 \\
RFG1 & Gulati and Nobile, 2016 \\
RLM1 & Marak and Dhanashree, 2018; \\
ROB1 & Burgain et al., 2019 \\
& Orsi et al., 2014; Marak and \\
TEC1 & Dhanashree, 2018; Burgain \\
& et al., 2019 \\
& Gulati and Nobile, 2016 \\
& Feng et al., 2016; Gulati and \\
& Nobile, 2016; Pierce et al., \\
& 2017; Tan et al., 2017 \\
\hline & \\
&
\end{tabular}

The overexpression of Ywp1 protein in the cell wall makes the biofilm more adherent, as it negatively regulates the dispersion process. It has previously been shown that Ywp1 can collaborate biofilm detachment in early stages. On the contrary, it can contribute to biofilm maintenance during the late phases of biofilm growth. It has been proposed that Ywp1 interacts with other C. albicans adhesin proteins expressed in early, but not late phases of biofilm growth (Karkowska-Kuleta et al., 2019).

The process of cell dispersion begins early and occurs during the development phase of the biofilm. These dispersed cells have differences in their transcriptome that confer improved virulence characteristics and drug resistance, as well as a superior expression of transporters necessary for the achievement of nutrients. However, initial adhesion and maintenance are keys to biofilm biomass development. The filamentation process is important for the expression of proteins that maintain adhesion, and thus the deletion of individual proteins in C. albicans, such as Efg1 and Bcr1, resulted in an almost complete loss of initial adhesion and a collapse of biofilm development. However, the suppression of the expression of the ALS1 and ALS3 adhesins and Hyr1 lead to a shortage of adhesion and biofilm biomass.
The hyperfilamentous strains generated by the suppression of Hog1 and Sfl1, formed a more robust biofilm. In addition, in a previous study, it was found that C. albicans that lacks Ywp1 protein had a weak adhesion maintenance force, but its effect on initial binding was minimal. This finding indicates that Ywp1 protein interferes with other C. albicans adhesive proteins (McCall et al., 2019).

The proteins expressed in Candida spp. biofilm formation are summarized in Table 2.

\section{Quorum Sensing (QS)}

Quorum sensing or "quorum perception" designates a complex intercellular communication system, wherein the microorganisms coordinate to generate a uniform response for their survival and ensure the colonization of their habitats. It is the so-called "language of microorganisms" (Saxena et al., 2019).

Due to the environment, the metabolic pathways of C. albicans that are involved in the yeast-hypha transition, as well as its virulence, depend on a large number of molecules generated during QS (Padder et al., 2018). This process includes the production and deliverance of a signal molecule (autoinducer) that, according to cell density, will increase its concentration and favor the collective and synchronized expression of specific genes in all the species associated with biofilm formation.

According to Riekhof and Nickerson (2017), it has been demonstrated that $C$. albicans is a dimorphic fungus in the presence of farnesoic acid (FA) and farnesol (F), the two sensor molecules of related sesquiterpene quorums, and when accumulated, they do not allow the change from yeast to mycelium. Studies were conducted with three different ATCC strains of C. albicans, 10231, A72, and SC5314. The first strain excretes a high concentration of FA, while the remaining two secretes only F, although it is important to note that the Candida

TABLE 2 | Differential expression of the proteins involved in biofilm formation in Candida spp.

\begin{tabular}{lll}
\hline Type & Protein & References \\
\hline Adhesion & Adhesins & Nett et al., 2015; Hirota et al., \\
& Als1 & Diezmann et al., 2015 \\
& Als3 & Diezmann et al., 2015 \\
& Bcr1 & Diezmann et al., 2015 \\
& Efg1 & Diezmann et al., 2015 \\
Hog1 & Diezmann et al., 2015 \\
& Hyr1 & Diezmann et al., 2015 \\
Sfl1 & Diezmann et al., 2015 \\
Ywp1 & Becherelli et al., 2013; Diezmann \\
& et al., 2015 \\
Alarmin S100-A9 & Beitelshees et al., 2018 \\
C-reactive protein & Beitelshees et al., 2018 \\
& eDNA & Thomas et al., 2006 \\
Hemoglobin & Beitelshees et al., 2018 \\
Myeloperoxidase & Beitelshees et al., 2018 \\
Heat shock & Wagener et al., 2012; Willaert, \\
& 2018 \\
\hline
\end{tabular}


spp. that produce FA do produce $\mathrm{F}$ in undetectable amounts. In conclusion, although $\mathrm{F}$ and FA possess close chemical similarity, they use separate pathways to block hyphal development.

Previously, CaPHO81, a key component of the phosphate starvation response signal transduction pathway, has been shown to be implicated in inhibition of hyphal development via FA. First, it must be taken into account that the $\Delta$ hot 1 mutant cells used in this study, lost their sensitivity to FA but were still sensitive to F. Second, HOT1 and PHO81 mRNA abundance increased dramatically between 40 and $240 \mathrm{~min}$ after FA treatment, but these expression levels remained unchanged after $\mathrm{F}$ treatment as well. However, the genetic and biochemical factors that contribute to the selection for FA production versus F production are currently unexplored. Moreover, further studies will likely provide more details on the differences in virulence and immune responses between the ATCC 10231 strain used in various studies and other clinical isolates of C. albicans (Dižová and Bujdáková, 2017; Paluch et al., 2020).

Farnesol synthesized by $C$. albicans acts as a negative regulator of morphogenesis, as it inhibits the yeast-hyphae transformation. Thus, the aforesaid effect on morphological transformation via cyclic AMP (cAMP)/protein kinase A (cAMP-PKA) pathway also affects other biochemical pathways of yeasts, such as the ones for sterol biosynthesis or triggering of apoptosis via accumulation of ROS (reactive oxygen species) that damages essential cellular compartments. ROS activate intracellular caspases that indicate apoptotic response in C. albicans (Lindsay et al., 2012; Polke et al., 2018).

Regarding QS, we would like to highlight that Paluch et al. (2020) investigated the quorum quenching (QQ) technique and highlighted its importance because it interrupts the microbial communication and ultimately, the biofilm formation. QQ-driving molecules can decrease or even completely inhibit virulence factor production, and consequently, biofilm formation. One of the strategies is to use structural analogs of the QS receptor autoinducers. Most QQ molecules are enzymes with the ability to degrade the signaling molecules or cascades. The techniques that are being used to measure QS/QQ are mass chromatography-spectroscopy, bioluminescence, chemiluminescence, fluorescence, electrochemistry, and colorimetry. The importance of these research methods lies in their medical and biotechnological application.

\section{Candida BIOFILM MODELS}

To determine whether Candida spp. can form biofilms on vaginal mucosa, the use of in vivo, ex vivo, and in vitro models are essential. Studying the implications of Candida spp. in clinical practice may help in the discovery of new therapeutic targets in Candida spp.

\section{In vitro Models}

To facilitate the detection of compounds that are active against biofilms, high-performance biofilm models are needed. Tsui et al. (2016) used a microtiter plate model to evaluate the variability between C. albicans biofilms formed in independent wells of the same microtiter plate. The biofilms that constituted over a $24 \mathrm{~h}$ period showed consistent metabolic activity.

Nweze et al. (2012) and Almshawit et al. (2014) used the Calgary Biofilm Device (CBD) for the understanding of Candida spp. biofilms. The CBD was also used to study the susceptibility of Candida spp. biofilms to metal ions and chelating agents (Harrison et al., 2007a) and identify persistent cells in such biofilms (Harrison et al., 2007b).

Samaranayake et al. (2005) used a perfusion model involving three commonly used antifungal agents, amphotericin B, fluconazole, and flucytosine, and biofilms established on microporous filters by C. albicans, C. parapsilosis, and C. krusei. The authors found that biofilm growth is dependent both on the antimycotic agent used and Candida spp. Shao et al. (2015) described a free-flow incubator that allowed biofilm organization under continuous flow conditions. The system displayed stability and continuity during the $96 \mathrm{~h}$ experiment. C. albicans and C. glabrata might co-exist in the dual-species biofilms under the flow regime.

Catheter-associated infections can be caused by biofilms formed on catheter surfaces. Within the biofilm, cells are protected from the host immune system. Authors studied the formation of $C$. albicans biofilms on catheters, including latex urinary catheters, and with artificial urine and antimicrobial therapies (Negri et al., 2011).

Recently, Srinivasan et al. (2012) have developed a C. albicans biofilm chip microarray system (CaBChip). The system is composed of more than 700 uniform and independent nanobiofilms encapsulated in a collagen matrix and is the first miniature biofilm model for $C$. albicans. In spite of multiple miniaturizations, the biofilms formed on the chip had phenotypic features that were similar to those of biofilms organized in vitro, containing a combination of yeast, pseudohyphae, and hyphal cells, and high concentrations of antifungal compounds. The models will allow the identification of possible antibiofilm drugs.

The use of SkinEthic ${ }^{\mathrm{TM}}$ reconstituted human epithelia models is based on the fact that the epithelial cells are placing in inert filter substrates that rise to the air-liquid interface in a humidified air incubator. Nutrient medium is added to feed the basal cells through the filter substrate. After the first 5 days, a stratified epithelium similar to human tissue is formed. The oral and vaginal epithelial tissues formed express all the major natural markers of epithelial basement membrane and epithelial differentiation, behave like human epithelium, and reflect natural wound resolution processes in vivo. Damage can be visualized by histopathological examination and precisely analyzed using available techniques. Confocal laser microscopy is being used (Schaller et al., 2003, 2005), although no conclusive data have yet been published.

Samaranayake et al. (2005) and other authors have verified that Candida spp. biofilms on mucosal surfaces exhibit characteristics similar to those of cells growing on abiotic surfaces. Murine models with vaginal yeast infections established on mucosal surfaces have demonstrated that Candida biofilms harbor many yeast, hyphae, and extracellular material. 
Table 3 shows the main studies on Candida biofilm models conducted in vitro.

\section{In vivo Models}

Experimental animal models are crucial to completely understand the candidate factors of pathogenesis and develop new therapeutic approaches, mainly in light of the increased incidence of fungal infections.

Rodents are one of the most useful animals to study candidiasis, since the disease process and host immune responses are similar to those of humans. A well-established estrogendependent mouse model has been developed for the study of vaginitis (Yano and Fidel, 2011). Even though, unlike humans, laboratory rodents do not naturally have $C$. albicans as a commensal, the experimentally induced infection resembles human infection. Therefore, the investigations of the animal model are translatable to the human host (Peters et al., 2014).

Wang and Fries (2011) made a murine model to investigate catheter-associated urogenital tract infections and candiduria. In this model, a guidewire is inserted through the urethra of a female mouse and a catheter segment is inserted over the guidewire into the bladder. While mucosal biofilms share many characteristics with the device-associated biofilms, whether they exhibit the same degree of resistance to antifungal compounds is unclear. Clinically, mucosal biofilms respond more frequently to antifungal therapies, including azoles (Wang and Fries, 2011).

After 5-7 days, the animal is infected intravascularly with C. albicans. The infection persists for approximately 28 days.
During this time period, a dense biofilm of adherent yeast and hyphae forms on the luminal and extraluminal surfaces. The difficulty is that, since there is only one catheter segment, the flow will probably be less. This system can also be used in other mammalian animals, including wild or immunocompromised animals.

Since there is only one catheter segment in place in the model, the flow conditions are probably less than what would be seen for a catheter installed in a patient, which functions to drain the bladder. The model includes the mammalian immune system. In addition, the model may use wild type or immunocompromised animals. To the best of our knowledge, this model has not been used to investigate the activity of anti-biofilm therapies yet.

Naglik et al. (2008) administered $0.1 \mathrm{mg} 17-\beta$-oestradiol in $0.1 \mathrm{ml}$ sesame seed oil subcutaneously for 3 days to female mice prior to intravaginal inoculation with $20 \mu \mathrm{l}$. albicans 3153A $\left(2.5 \times 10^{6}\right.$ cells $\left./ \mathrm{ml}\right)$, C. albicans DAY185 $\left(2.5 \times 10^{8}\right.$ cells $\left./ \mathrm{ml}\right)$, or biofilm mutant $\left(2.5 \times 10^{8}\right.$ cells $\left./ \mathrm{ml}\right)$ suspension. After a period of time, the mice were euthanized. The vagina was removed from each mouse and examined through confocal or scanning electron microscopy.

Harriott et al. (2010) performed an ex vivo investigation that involved female mice treated with estrogen. After euthanizing, the vagina was removed from each mouse. C. albicans isolates $\left(1 \times 10^{6}\right.$ blastoconidia) in $0.1 \mathrm{ml}$ PBS was incubated at $37^{\circ} \mathrm{C}$ in an atmosphere of $\mathrm{CO}_{2}$ and instilled on the vaginal surface. The fungal load was determined and microscopy examination was performed.

TABLE 3 | Schema for in vitro Candida spp. related to biofilm models.

\begin{tabular}{|c|c|}
\hline In vitro models & Components \\
\hline Plastic/microtiter plates (Tsui et al., 2016) & $\begin{array}{l}\text { Polystyrene surfaces at different temperatures ( } 10 \text {, } \\
\left.20 \text {, and } 37^{\circ} \mathrm{C}\right) \text {, flat-bottomed } 96 \text {-well microtiter } \\
\text { plates, and plastic slides }\end{array}$ \\
\hline $\begin{array}{l}\text { Calgary Biofilm Device (CBD) (Harrison et al., } \\
\text { 2007a; Nweze et al., 2012; Almshawit et al., 2014) }\end{array}$ & $\begin{array}{l}\text { CBD was developed from polypropylene } \\
\text { microcentrifuge tubes and pipette type boxes, as } \\
\text { well as } 96 \text {-well polystyrene pegs/plates }\end{array}$ \\
\hline Microporous membrane filters (Gu et al., 2015) & Microporous polycarbonate (25-mm diameter) \\
\hline
\end{tabular}

Flow system biofilm models (Shao et al., 2015)

Catheters (Negri et al., 2011)

Robotic microarrayer is used to dispense yeast cells of $C$. albicans onto a solid substrate. (CaBChip) (Srinivasan et al., 2012, 2013)

Reconstituted human epithelia (RHE) models (Schaller et al., 2003, 2005)
Automated microfluidic device under laminar flow conditions

Silicone, polyurethane, and latex urinary catheters, with artificial urine

CaBChip composed of $\sim 750$ equivalent and spatially distinct biofilms with cell-based microarray platform allows for miniaturization of microbial cell culture and is fully compatible with other high-throughput screening technologies

Epithelial cells are seeded on inert filter substrates that are raised to the air-liquid interface in a humidified air incubator

\section{Characteristics}

Useful for biofilm formation for different Candida spp. strongly associated with the type and phenotypic behavior of the isolates

A useful, simple, low cost miniature device for parallel study of Candida biofilms and factors modulating this phenomenon.

Quantitative evaluation of the antifungals that diffused into the disk through the biofilm

Used to study biofilm formation in real-time. The flow of liquids can influence nutrient exchange and the structural integrity of biofilms.

Used under flow conditions to study Candida spp. adhesion and biofilm formation

The main advantages of the fungal biofilm chip are automation, miniaturization, savings in amount and cost of reagents and analyses time, as well as the elimination of labor intensive steps. This chip significantly speeds up the antifungal drug discovery process.

Epithelial damage can be visualized by histological analysis of the embedded and quantified based on the extracellular activity of lactate dehydrogenase $(\mathrm{LDH})$ in the culture medium released by the damaged epithelial cells. Additionally, microscopy. fluorescence-activated cell sorting. ELISA can be used to measure and detect protein expression, and real-time immune-PCR (used to show them) 
Another recently used model for the in vivo study of Candida spp. biofilms is the nematode Caenorhabditis elegans. The model is relevant for aspects of human infections, including resistance to antifungal agents (Madende et al., 2020).

The most relevant studies on Candida in vivo/ex vivo biofilms are summarized in Table 4

\section{Biofilm Inhibition}

It should be noted that despite the existence of numerous investigations, no specific drugs are available for treating biofilmproduced VVC/RVVC yet.

Posaconazole shows in vitro and in vivo synergy with caspofungin against C. albicans, including echinocandinresistant isolates. Furthermore, an in vitro study of C. albicans, C. glabrata, and C. parapsilosis showed that azole-resistant Candida spp. are not resistant to the combination of both compounds (Cui et al., 2015). Similar results were obtained by Ning et al. (2015) with epigallocatechin gallate bound to azoles.

In a study of the various biological properties of the thiazolidinone scaffold, 100 compounds were synthesized and characterized by a 1,3-thiazolidin-4-one nucleus derivatized at the $\mathrm{C} 2$ with a hydrazine bridge, linked to (cyclo) aliphatic or hetero (aryl) moieties. The $N$-benzylated derivatives of these compounds were found to be highly effective against Candida spp. (Carradori et al., 2017).

Mannich base-type eugenol derivatives have also been synthesized and shown to be particularly effective against C. glabrata (Abrão et al., 2015).

Piperazine derivatives $1 \mathrm{c}-34 \mathrm{e}$ have been synthesized from phenol, 2,4-dichlorophenol and 4-hydroxybiphenyl. Their inhibitory activity during hyphae formation was verified and it correlated with the inhibition of biofilm formation by C. albicans, thus possibly indicating the vital role of hyphae development in the C. albicans biofilm formation process (Zhao et al., 2018).

A new series of glycosides modified in their saccharide units has been analyzed against Candida sp. The newly synthesized glycoside is called eugenol glucosiso 5 and can be considered a new structural pattern in anti-Candida drugs, fundamentally against C. glabrata (de Souza et al., 2016).
When a cationic peptide antibiotic was used in combination with antifungal agents, such as polymyxin B with azoles, a synergist effect was seen (Pankey et al., 2014; Raman et al., 2015). Aminoglycosides, like tobramycin, have been shown to possess antifungal potential (Fosso et al., 2018). Silva et al. (2014) showed that cerium nitrate has fungicidal activity against planktonic Candida cells. Similarly, the ability of cerium nitrate to pare and disarticulate biofilms has been demonstrated, which represents an important advance in clinical practice. Thamban Chandrika et al. (2018) identified fluconzaol analogs and found that the antifungal activity of alkyl-amino fluconazole derivatives depends on the alkyl chain length. Recently, compounds 6-9 were identified as promising antifungal agents, with low cytotoxicity and hemolytic activity. These compounds have higher activity levels and lower toxicity than fluconazole.

Antifungal lock therapy is used to inhibit biofilm formation. Micafungin (5 and $15 \mathrm{mg} / \mathrm{L}$ ), especially combined with ethanol; capsofungin (5 and $25 \mathrm{mg} / \mathrm{L})$; and posaconazole $(10 \mathrm{mg} / \mathrm{L})$ have been used in this form of therapy (Walraven and Lee, 2013). Liposomal amphotericin B (5 mg/mL) or anidulafungin (3.33 mg/mL) has also been successfully used (Basas et al., 2019).

Nikkomycin $\mathrm{Z}$ has been shown to act synergistically in association with caspofungin or micafungin against biofilms (Kovács et al., 2019).

Given the resistance of fungi to fluconazole, new compounds derived from this antifungal compound have been investigated. A total of 27 new fluconazole derivatives have been tested for their antifungal activity against a panel of 13 clinically relevant fungal strains (Shrestha et al., 2017).

Classically, the combination of antifungals and antibiotics, such as rifampicin, have been shown to have a general role in regulating signal transduction or modulating gene expression by other mechanisms in C. albicans (Vogel et al., 2008). Similarly, synergistic interactions between fluoroquinolones and antifungal agents (amphotericin B or caspofungin) have been demonstrated, potentially improving the outcome in immunosuppressed patients with concurrent bacterial and fungal infections (Stergiopoulou et al., 2009). Recently,

TABLE 4 | Schema for in vivo/ex vivo Candida-associated urogenital biofilm models.

\begin{tabular}{|c|c|c|c|c|}
\hline In vivo models & Device & Animal species & Characteristics & References \\
\hline Catheter-associated models & $\begin{array}{l}\text { Candiduria model: a } \\
\text { subcutaneous foreign body } \\
\text { system featuring a catheter } \\
\text { through the urethra of a female } \\
\text { mouse }\end{array}$ & Rat, mouse, and rabbit & $\begin{array}{l}\text { Rat and mouse models have } \\
\text { advantages over rabbit } \\
\text { models that include relatively } \\
\text { low cost, ease of use, and } \\
\text { ability to mimic the clinical } \\
\text { conditions of rabbit models }\end{array}$ & $\begin{array}{l}\text { Wang and Fries, } 2011 \\
\text { Yano and Fidel, } 2011 \text {; } \\
\text { Peters et al., } 2014\end{array}$ \\
\hline $\begin{array}{l}\text { Models in which the vagina of } \\
\text { each animal is excised and cut } \\
\text { longitudinally to expose the } \\
\text { mucosal surface. }\end{array}$ & $\begin{array}{l}17-\beta \text {-Estradiol } \\
\text { subcutaneous + intravaginally } \\
\text { administered C. albicans }\end{array}$ & Female mice & $\begin{array}{l}\text { Tissue is used to determine } \\
\text { fungal load through } \\
\text { confocalor scanning electron } \\
\text { microscopy }\end{array}$ & Naglik et al., 2008 \\
\hline $\begin{array}{l}\text { Models using biotic surfaces, } \\
\text { such as vaginal mucosa }\end{array}$ & Ex vivo models & $\begin{array}{l}\text { Mouse (treated with estradiol } \\
\text { prior to infection) }\end{array}$ & $\begin{array}{l}\text { Low cost and mimics clinical } \\
\text { conditions }\end{array}$ & Harriott et al., 2010 \\
\hline $\begin{array}{l}\text { Animal is infected with fungi by } \\
\text { consuming the yeast cells as a }\end{array}$ & In vivo models & $\begin{array}{l}\text { Nematode Caenorhabditis } \\
\text { elegans }\end{array}$ & $\begin{array}{l}\text { Identification of antifungal } \\
\text { chemical compounds }\end{array}$ & Madende et al., 2020 \\
\hline
\end{tabular}

food source 
chloramphenicol has been shown to have activity, mainly against C. albicans and C. glabrata (Joseph et al., 2015). The combination of antifungals and QS molecules is also of interest. Farnesol, a QS molecule, inhibits the formation of hyphae and biofilms, and tyrosol and farnesol are excellent antifungal candidates (Monteiro et al., 2017; Mehmood et al., 2019).

Using nanotechnology, amphotericin B-loaded silver nanoparticles have been developed and shown promise in improving the antifungal capacity of amphotericin B against Candida spp. (Leonhard et al., 2018).

Some success has also been obtained with $0.43-1.736 \mathrm{mM}$ acetylsalicylic acid use. It is especially effective due to its synergistic effects with amphotericin B (Zhou et al., 2012). Ibuprofen (Sharma et al., 2015) and ambroxol (Li et al., 2017) have also been successfully used as antifungal agents.

Synthetic compounds, such as the peptides, KSL-W and SM21, which inhibit the transition from yeast to hypha, also inhibit biofilm formation (Theberge et al., 2013; Cavalheiro and Teixeira, 2018).

Photodynamic therapies using light of a certain wavelength and a photosensitizing dye are also being investigated. These therapies produce reactive oxygen species (ROS), and after treatment, substances such as hydrogen peroxide can be used. The absence of dye toxicity and low cost of the technique suggest that this alternative approach has great potential (Bujdáková, 2016).

Polymers incorporated in medical devices can also be modified to prevent fungal contamination. Lumbrical organ water-insoluble polyethylamine derivatives are capable of inhibiting $C$. albicans growth, by altering the membrane integrity. Furthermore, the natural polymer, chitosan, is also effective against C. albicans biofilms (Hoque et al., 2015).

Table 5 shows the main advances in new compounds involving new therapeutic options directed toward fungal biofilms.

\section{Immune Response Intervention}

Peptide-derived antibody therapies against Candida spp. are currently being developed. These therapies increase the oxidative stress of the yeast and membrane permeability to significantly decrease the expression levels of biofilm generation-related genes (Paulone et al., 2017).

New targets are also being investigated to develop vaccines for RVVC. An effective RVVC vaccine is a possible option to treat this chronic condition. An ideal vaccine should be able to induce an efficient immune response that promotes fungus elimination and virulence factor neutralization, without causing harmful changes in the vaginal microenvironment (Cassone, 2015). Vaccines that target the adhesin, Als3, and the enzyme, Sap2, have been developed. Although no vaccine has been approved for use in humans currently, important advances in this area are expected in the near future (Sui et al., 2017; Tso et al., 2018). In a recent study, 70 women of fertile age were recruited and divided into two groups. One group was treated by intravaginal autolymphocyte therapy, in conjunction with traditional treatment, and a control group only received conventional treatment. The group of patients treated by autolymphocyte therapy recovered fully in half the time than that required by the control group (Alyautdina and Esina, 2019).

\section{Probiotics}

The term probiotics refers to microorganisms with beneficial actions on the human body. To be classified as a probiotic, a microorganism must be correctly identified at the genus, species, and strain levels using phenotypic and genotypic methods, since the demonstrated beneficial effects of a specific strain cannot be extrapolated and attributable to another strain of the same species. The strain is also required to be deposited in an internationally recognized collection. Probiotics should lack virulence factors and/or the ability to produce metabolites that are undesirable for the host. The main objective of probiotic therapy is not to re-establish the vaginal canal bacterial microbiome; and there is no consensus for its use in vaginal infection treatment or their sequelae (Hewadmal and Jangra, 2019). However, Rodríguez-Cerdeira et al. (2019) have extensively reported the importance of probiotics in VVC/RVVC treatment. Ongoing research on this topic and recently performed studies are discussed below.

Tsimaris et al. (2019) studied a group of 70 women treated with Lactobacillus during the pre-diagnosis period. Administration of intravaginal $B$. coagulans, alone and in combination with standard antibiotic therapy, provided significant benefits in the treatment of vaginal symptoms in VVC patients in this clinical trial.

Previous studies support the notion that vaginal microbiota restoration and/or local mucosal immune response modulation can be achieved via supplementation with probiotics, which can be administered orally as a probiotic food supplement, intravaginally as vaginal suppositories, or applied topically as a gel (Köhler et al., 2012; Gille et al., 2016).

Gabrielli et al. (2018) have verified the probiotic capacity of Saccharomyces cerevisiae CNCM I-3856 to modulate the expression of $C$. albicans pathogenicity in mice with vaginal candidiasis. Daily intravaginal administration of $S$. cerevisiae CNCM I-3856 was shown to eliminate various components of the fungus necessary for its virulence in the vagina and modulate the expression of aspartyl proteinase and genes associated with hyphal growth, Hwpl and Ecel, in the epithelium. The decreased inflammatory response observed in this study was likely due to the decrease in IL-8 production and aspartyl proteinase expression inhibition. Despite the assumption that $S$. cerevisiae administration would produce undesirable effects, it did not alter the architecture of vaginal epithelial cells or organs, either in vitro or in the human vaginal epithelium in vivo (Handalishy et al., 2014; van de Wijgert and Verwijs, 2020).

In general, the studies reported contradictory results and probiotics were generally not effective in preventing or curing VVC. None of the studies showed safety issues with the tested probiotics. There was no evidence of vaginal colonization by the probiotic strains and thus, vaginal detection is restricted to the dosing period. It should be noted that the different probiotic products used in these studies differ in their components, such as the active ingredients and excipients, and the application methods and dosages differ between the different studies. There 
TABLE 5 | New anti-Candida spp. biofilm compounds.

Compound
Posaconazole plus caspofungin (in vitro and in animals)
or
Concomitant use of epigallocatechin gallate and
miconazole, fluconazole, or amphotericin B
1,3-thiazolidin-4-one nucleus and its N-benzylated
derivatives at the C2 with a hydrazine bridge linked to
(cyclo)aliphatic or hetero(aryl)
Mannich base-type eugenol derivatives: :
4-allyl-2-methoxy-6- (morpholin-4-ylmethyl) phenyl
benzoate (7) and 4- $\{5$-allyl-2 - [(4-chlorobenzoyl) oxy]
-3-methoxybenzyl\}. Morpholin-4-io (8) chloride was found
1-(4-ethoxyphenyl)-4-(1-biphenylol-2-hydroxypropyl)-
piperazine
Glucosides with modified saccharides
Amphiphilic, helical $\beta$-peptide structural mimetics of natural
antimicrobial $\alpha$-peptides
Aminoglocosides derived from tobramycin
Cerium nitrate, a member of the lanthanide family

Fluconazole analogs with alkyl-, aryl-, cycloalkyl-, and dialkyl-amino substituents

Micafungin + ethanol

Capsofungin/posaconazole, or

amphotericin $\mathrm{B}$, or

anidulafungin, or

Caspofungin/micafungin in combination with nikkomycin Z

27 new FLC derivatives

Fluoroquinolones and antifungal agents (from amphotericin B or caspofungin) or rifampicin

Chloramphenicol

Tyrosol and farnesol

Amphotericin B plus silver hybrid nanoparticles

Amphotericin B plus acetylsalicylic/ibuprofen/ambroxol

KSL-W and SM21 peptides

\section{Action}

C. albicans, C. glabrata, and C. parapsilosis

Highly effective against C. albicans, C. glabrata and C. parapsilosis

in vitro and in animal experiments

Strong activity against Candida spp.

Lack of cytotoxic effects

Highly effective against C. albicans, C. glabrata, and C. krusei

Acts primarily on C. albicans

Low cytotoxic effects

Fungistatic activity against C. glabrata

Specific planktonic antifungal and anti-biofilm activity against

C. albicans, C. glabrata, C. parapsilosis, and C. tropicalis

The triazole is most effective against Candida spp.

Active against planktonic and sessile Candida spp. cells

It is able to prevent biofilm formation by $C$. albicans and

C. parapsilosis both in vitro and in vivo

Application in medical devices

These compounds are active against some of the C. albicans and non-albicans Candida strains and are highly effective against clinical strains of C. glabrata and C. parapsilosis

Antifungal lock therapy is used to inhibit the formation of the biofilm

Broad-spectrum antifungal activity. All compounds inhibit the sterol $14 \alpha$-demethylase enzyme involved in ergosterol biosynthesis

very useful in immunosuppressed patients

Not valid for use against C. albicans or C. glabrata Antifungal activity comparable to caspofungin and ketoconazole

Strong biofilm inhibition Inhibit the formation of hyphae

Powerful antifungal activity although the toxicity of the nanoparticles depends on the size, concentration, and $\mathrm{pH}$ of the medium and the exposure time to pathogens

They are inexpensive, but they increase the risk of bleeding and hyperkalaemia

Inhibit biofilm formation by Candida spp.
References

Cui et al., 2015

Ning et al., 2015

Carradori et al., 2017

Abrão et al., 2015

Yano et al., 2012

Zhao et al., 2018

de Souza et al., 2016

Pankey et al., 2014

Raman et al., 2015

Fosso et al., 2018

Silva-Dias et al., 2015

Thamban Chandrika et al., 2018

Walraven and Lee, 2013

Basas et al., 2019

Kovács et al., 2019

Shrestha et al., 2017

Stergiopoulou et al., 2009

Vogel et al., 2008

Joseph et al., 2015

Monteiro et al., 2017

Mehmood et al., 2019

Leonhard et al., 2018

Zhou et al., 2012

Sharma et al., 2015

Li et al., 2017

Theberge et al., 2013

Cavalheiro and Teixeira, 2018 is also no consensus on which specific strains of Lactobacillus may be most beneficial for dysbiosis. However, the efficacy of the different probiotics analyzed in the studies was highly similar.

\section{DISCUSSION}

The importance of the present review lies in the fact that it raises awareness regarding the impact of biofilms on practical clinical management and treatment of VVC/RVVC and highlights the need for additional research toward the development of novel therapeutics targeting pathogenic vulvovaginal biofilms.

As discussed in the present review, numerous transcriptional events related to morphogenesis, key molecule expression, and virulence factor manifestation occur during the invasion and infection processes. Experimental evidence indicates that C. albicans can differentially regulate its genes during adaptation to and subsequent colonization of a biological niche, and it exhibits a specific profile of virulence factors depending on the type of mucosa in which the infection occurs. In this 
review, we focussed on the mucosa of the lower genital tract (TGI) with a special emphasis on the vulvovaginal mucosa (El-Houssaini et al., 2019).

Candida spp. that form biofilms exhibit high resistance to antifungal drugs and are known to successfully evade host defense mechanisms. This resistance is responsible for the perpetuation and reappearance of this type of infection, causing collateral damage to the surrounding tissues.

Present interventions for preventing biofilm formation are based on attempts to modulate surface chemistries to ensure prevention of attachment (Li et al., 2018) or blocking molecules involved in signal transduction, such as c-diGMP, from regulating attachment and matrix production (Hall and Lee, 2018).

Other substances used are proteases immobilized on a polypropylene surface, which decreases the adhesion of C. albicans required for biofilm formation, although the toxicity of these enzymes remains an issue (Andreani et al., 2017).

Disruption of the maturation of Candida biofilms with the alkaloid berberine has been successfully demonstrated in both planktonic and biofilm conditions, as described by Xie et al. (2020). The authors observed significant alterations in the architecture of biofilms formed by C. albicans (ATCC 10231 and ATCC 90028), C. krusei (ATCC 6258), C. glabrata (ATCC 90030), and C. dubliniensis (MYA 646).

The role of epithelial cell-mediated immunity of the vulvovaginal mucosa is crucial in the context of protection against vaginal Candida infections. The FGT is equipped with various mechanisms responsible for innate immunity that are important in maintaining immunological surveillance against microorganisms, upholding the basic tenets of commensalism, and ensuring protection against invasion (Cassone, 2018). These include neutrophil polymorphonuclear cells (PMNs), macrophages, dendritic cells, natural killer (NK) cells, T lymphocytes, and innate lymphocytes, which actively contribute to the localized antifungal response (Richardson et al., 2018; Yano et al., 2018). Most of these cells reside in the mucous membranes of the TGI, although additional molecules are recruited in response to infection. In addition to the transforming growth factor (TGF) involved in immunoregulation, epithelial cells express innate immunity receptors, such as pattern recognition receptors (PRRs) and a broad spectrum of antimicrobial peptides including alarmins, chemokines, and cytokines [such as IL-1, IL-6, IL-8, and tumor necrosis factor (TNF)]. All these factors initiate the first phase of the response and contribute to the recruitment of other cell populations (Doerflinger et al., 2014; Pericolini et al., 2015).

Epithelial cells can discern between the saprophytic and hyphal forms of $C$. albicans, leading to activation of the inflammatory response if necessary. Yeast to hypha transition and virulence factor production causes epithelial disruption and results in PMN recruitment, which, in turn, exacerbates the inflammation (Yano et al., 2018). Previous studies have identified the alarmins, S100A8 and S100A9, as key chemotactic mediators of the acute PMN response toward Candida infection (Yano et al., 2012).

According to Jaeger et al. (2013), epithelial cells express PRRs, which are capable of detecting the presence of microorganisms and sending activation signals to induce immune mediator secretion. There are 3 PRR families involved in the recognition of Candida pathogen-associated molecular patterns (PAMPs). The different PAMPs of Candida spp. recognized by these PRRs are well-characterized. Toll-like receptors (TLR)2, TLR4, TLR7, and TLR9 recognize phospholipomannans, O-mannosiderich structures, Candida RNA, and Candida DNA, respectively. NOD-like receptors (NLRs) are found in the cytosol of cells. NLRP3 constitutes a part of the inflammasome, which is a cytoplasmic multiprotein complex with enzymatic activity. Other receptors, such as mannose receptor, dectin-2, DC-SIGN, and mincle recognize other glucidic structures, such as mannose and fucose, located in the Candida cell wall (Stoddart et al., 2011; Yano et al., 2018).

As described by Yu and Gaffen (2008), Th17 cells within the $\mathrm{CD}^{+} \mathrm{T}$ lymphocyte population secrete IL-17A, IL-17F, IL-22, and IL-263, but differ in their production of cytokines such as IL-1, IL-6, and TGF3. IL-23 is an absolute requirement for the expansion, maintenance, and effector functions of this cell population. NKT cells, T lymphocytes, and group 3 innate lymphoid cells (ILC3s) produce abundant IL-17 and play important roles in defending the mucosa (Conti et al., 2009).

Identification of the key role of morphogenic changes in fungus and production of Sap as a virulence factor that activates the local inflammatory response have been associated with the discovery of mutations and genetic polymorphisms in the PRRs (Kalia et al., 2019) and their activation pathways. These observations collectively highlight the mechanism of VVC pathogenesis.

Biofilm formation in RVVC is usually related to the host immune system, when evasion of the defense system occurs at both humoural and acquired levels. Complement activation is known to be decreased in biofilms compared to that in plankton cells, and altered phagocytosis occurs due to the surrounding extracellular matrix of polymeric substances (Duggan et al., 2015).

It is important to highlight that persister cells that remain latent inside the biofilm evade elimination by macrophages (Mina and Marques, 2016; Wuyts et al., 2018). Therefore, understanding the contributions of these biofilms in fungal burden and in shaping subsequent strategies that influence and modulate the local immunopathogenic response is imperative for the development of efficient therapeutic modalities.

Emerging therapeutic approaches have centered on harnessing the complex interaction between commensal and pathogenic organisms in the vaginal environment. This is implemented mainly by diets rich in probiotics or vaginally administered probiotics, and this has been shown to restore the vaginal microbiota and decrease the incidence of VVC/RVVC. The work of Miyazima et al. (2017) provides support to these claims.

Combinations of prebiotics and probiotics, also called symbiotics, not only have therapeutic applications in infections in the intestinal tract but also for the urogenital area (Olveira and González-Molero, 2016).

Special care is taken with infections associated with mucosal devices (Nett, 2016). In these cases, inhibition of yeast adhesion to surfaces or devices (coating surfaces) constitute an important 
therapeutic aspect for patients with a catheter or similar device inserted in the urogenial tract (Palmieri et al., 2018).

Novel associations, emerging drugs, and new activities are being studied in response to yeasts in Candida spp. biofilms, as described in the previous section (Fosso et al., 2018; Thamban Chandrika et al., 2018; Černáková et al., 2019).

The resolution of these challenges would enable important advances in understanding and therapeutic management of this mycosis. Here, we summarize the potential therapeutic targets in three parts: (a) those aimed at inhibiting or eliminating biofilms, (b) those intervening in the immune response, and (c) those mediated by probiotics.

\section{CONCLUSION}

Mycological diagnosis requires a comprehensive knowledge of the complex mechanisms underlying the interaction between a fungus and its host, and the identification of fungi is not solely limited to complete and fine technical handling in the laboratory. Fungi are eukaryotic entities with a markedly more intricate physiology and pathophysiology than viruses or bacteria, and they are an increasingly frequent cause of morbidity and mortality.

Rapid and accurate identification of pathogenic yeasts is an objective in proper patient management, especially for fungal infection control. Incorporation of modern methodologies based on molecular, genomic, proteomic, and genetic engineering techniques has facilitated the identification of different strains of Candida spp. These methodologies have contributed toward preventing the irrational use of antifungals and selecting appropriate empirical therapy.

Candida spp. biofilms have considerable clinical repercussions in VVC/RVVC owing to the increasing frequency in resistance to antifungals presented by these patients. The capacity of Candida spp. strains to acquire resistance confers various advantages, such as the colonization of host tissues, expression of virulent characteristics, metabolic cooperation, efficient capture of nutrients, cell-cell communication, and exchange of genetic material, which provide a considerable ecological advantage, as it protects against antifungals.

Thus, the genes involved in biofilm formation and development as well as the quorum-sensing systems are considered new targets in the development of specific inhibitors as an alternative to currently available treatments.

\section{REFERENCES}

Abrão, P. H., Pizi, R. B., de Souza, T. B., Silva, N. C., Fregnan, A. M., Silva, F. N., et al. (2015). Synthesis and biological evaluation of new eugenol mannich bases as promising antifungal agents. Chem. Biol. Drug Des. 86, 459-465. doi: 10.1111/cbdd. 12504

Achilles, S. L., Austin, M. N., Meyn, L. A., Mhlanga, F., Chirenje, Z. M., and Hillier, S. L. (2018). Impact of contraceptive initiation on vaginal microbiota. Am. J. Obstet. Gynecol. 218, 622.e1-622.e10. doi: 10.1016/j.ajog.2018.02.017

Agustín, M., Viceconte, F. R., Vela Gurovic, M. S., Costantino, A., and Brugnoni, L. I. (2019). Effect of quorum sensing molecules and natamycin on biofilms of Candida tropicalis and other yeasts isolated from industrial
The ability of yeasts of the genus Candida to generate a biofilm is multifactorial and generally considered to be dependent on the site of infection, species and strain involved, and microenvironment in which it develops. Thus, as presented in this manuscript, the virulence attribute is not exclusive to a particular Candida species and new strains with greater formative capacity may emerge any time.

Although the in vitro systems studied in the present study had certain limitations, they allowed simultaneous processing of a large number of samples, which is ideal for screening. The systems also enabled easy testing of various physicochemical and biochemical parameters as well as studying the activity of antimicrobial agents. From a genomic point of view, the systems allowed us to analyze the genes involved in biofilm regulation and formation in the strains capable of forming biofilms (in situ).

In vivo studies in murine $\mathrm{VVC} / \mathrm{RVVC}$ models are commonly used to study C. albicans infection. Using these models, we will first investigate the virulence factors associated with Candida spp., including adhesins, aspartyl proteases, and hydrophobic properties. Second, we will analyze the factors favoring such infections, such as alterations in the bacterial flora. Third, we will examine the immune response to this infection in mice with genetic alterations. Finally, we can evaluate antifungal molecules through pharmacokinetic studies; prophylactic, therapeutic, and new molecule models; synergism studies; and in vitro, in vivo, and ex vivo correlation analyses.

The future of Candida spp. infection biology should simultaneously integrate the study of pathogenic factor analysis and host immunological characteristics to generate a comprehensive and detailed assessment of host-pathogen interactions. Therefore, the new VVC/RVVC approach aims to not only control fungal load, but also develop strategies targeted for modulating the local immunopathogenic response.

Finally, we must be particularly careful with immunocompromised patients with VVC/RVVC, as the release of new fungal cells from the biofilm may spread the infection throughout the body, which can lead to systemic candidiasis.

\section{AUTHOR CONTRIBUTIONS}

CR-C conceived, designed, and wrote the review. EM-H, MC$\mathrm{G}$, and AL-B provided the ideas and contributed to writing the manuscript. GF, MF, ME-S, and JG-C addressed the questions related to bibliography and summaries. All the authors have read and approved the final version of the manuscript.

juice filtration membranes. J. Appl. Microbiol. 126, 1808-1820. doi: 10.1111/ jam. 1424

Almshawit, H., Macreadie, I., and Grando, D. (2014). A simple and inexpensive device for biofilm analysis. J. Microbiol. Methods 98, 59-63. doi: 10.1016/j. mimet.2013.12.020

Alyautdina, O. S., and Esina, E. V. (2019). Immunological methods for treatment of vulvovaginal infections in the preconception period. J. Med. Life 12, 368-373. doi: 10.25122/jml-2019-0068

Andreani, E. S., Villa, F., Cappitelli, F., Krasowska, A., Biniarz, P., Łukaszewicz, M., et al. (2017). Coating polypropylene surfaces with protease weakens the adhesion and increases the dispersion of Candida albicans cells. Biotechnol. Lett. 39, 423-428. doi: 10.1007/s10529-016-2262-5 
Araújo, D., Henriques, M., and Silva, S. (2017). Portrait of Candida species biofilm regulatory network genes. Trends Microbiol. 25, 62-75. doi: 10.1016/j.tim.2016. 09.004

Araújo Paulo, de Medeiros, M., Vieira, de Melo, A. P., Maia, de Sousa, A. M., et al. (2017). Characterization of virulence factors of vaginal and anal isolates of Candida albicans sequentially obtained from patients with vulvovaginal candidiasis in north-east Brazil. J. Mycol. Med. 27, 567-572. doi: 10.1016/j. mycmed.2017.06.002

Ardehali, S. H., Azimi, T., Fallah, F., Aghamohammadi, N., Alimehr, S., Karimi, A. M., et al. (2019). Molecular detection of ALS1, ALS3, HWP1 and SAP4 genes in Candida genus isolated from hospitalized patients in Intensive Care Unit, Tehran, Iran. Cell. Mol. Biol. 65, 15-22.

Aznar-Marin, P., Galan-Sanchez, F., Marin-Casanova, P., García-Martos, P., and Rodríguez-Iglesias, M. (2016). Candida nivariensis as a new emergent agent of vulvovaginal candidiasis: description of cases and review of published studies. Mycopathologia 181, 445-449. doi: 10.1007/s11046-015-9978-y

Bandara, H. M., Cheung, B. P., Watt, R. M., Jin, L. J., and Samaranayake, L. P. (2013). Secretory products of Escherichia coli biofilm modulate Candida biofilm formation and hyphal development. J. Investig. Clin. Dent. 4, 186-199. doi: 10.1111/jicd.12048

Basas, J., Palau, M., Gomis, X., Almirante, B., and Gavaldà, J. (2019). Efficacy of liposomal amphotericin $\mathrm{B}$ and anidulafungin using an antifungal lock technique (ALT) for catheter-related Candida albicans and Candida glabrata infections in an experimental model. PLoS One 14:e0212426. doi: 10.1371/journal.pone. 0212426

Basmaciyan, L., Bon, F., Paradis, T., Lapaquette, P., and Dalle, F. (2019). Candida albicans interactions with the host: crossing the intestinal epithelial barrier. Tissue Barr. 7:1612661. doi: 10.1080/21688370.2019.1612661

Becherelli, M., Tao, J., and Ryder, N. S. (2013). Involvement of heat shock proteins in Candida albicans biofilm formation. J. Mol. Microbiol. Biotechnol. 23, 396400. doi: $10.1159 / 000351619$

Beitelshees, M., Hill, A., Jones, C. H., and Pfeifer, B. A. (2018). Phenotypic variation during biofilm formation: implications for anti-biofilm therapeutic design. Materials 11:1086. doi: 10.3390/ma11071086

Bitew, A., and Abebaw, Y. (2018). Vulvovaginal candidiasis: species distribution of Candida and their antifungal susceptibility pattern. BMC Womens Health 18:94. doi: 10.1186/s12905-018-0607-z

Blostein, F., Levin-Sparenberg, E., Wagner, J., and Foxman, B. (2017). Recurrent vulvovaginal candidiasis. Ann. Epidemiol. 27, 575.e3-582.e3. doi: 10.1016/j. annepidem.2017.08.010

Bradford, L. L., Chibucos, M. C., Ma, B., Bruno, V., and Ravel, J. (2017). Vaginal Candida spp. genomes from women with vulvovaginal candidiasis. Pathog. Dis. 75:ftx061. doi: 10.1093/femspd/ftx061

Brown, S. E., Schwartz, J. A., Robinson, C. K., O’Hanlon, D. E., Bradford, L. L., He, X., et al. (2019). The vaginal microbiota and behavioral factors associated with genital Candida albicans detection in reproductive-age women. Sex. Transm. Dis. 46, 753-758. doi: 10.1097/OLQ.0000000000001066

Bujdáková, H. (2016). Management of Candida biofilms: state of knowledge and new options for prevention and eradication. Fut. Microbiol. 11, 235-251. doi: 10.2217/fmb.15.139

Burgain, A., Pic, É, Markey, L., Tebbji, F., Kumamoto, C. A., and Sellam, A. (2019). A novel genetic circuitry governing hypoxic metabolic flexibility, commensalism and virulence in the fungal pathogen Candida albicans. PLoS Pathog. 15:e1007823. doi: 10.1371/journal.ppat.1007823

Carradori, S., Bizzarri, B., D’Ascenzio, M., De Monte, C., Grande, R., Rivanera, D., et al. (2017). Synthesis, biological evaluation and quantitative structureactive relationships of 1,3-thiazolidin-4-one derivatives. A promising chemical scaffold endowed with high antifungal potency and low cytotoxicity. Eur. J. Med. Chem. 140, 274-292. doi: 10.1016/j.ejmech.2017.09.026

Carrano, G., Paulone, S., Lainz, L., Sevilla, M. J., Blasi, E., and Moragues, M. D. (2019). Anti-Candida albicans germ tube antibodies reduce in vitro growth and biofilm formation of C. albicans. Rev. Iberoam. Micol. 36, 9-16. doi: 10.1016/j. riam.2018.07.005

Cassone, A. (2015). Vulvovaginal Candida albicans infections: pathogenesis, immunity and vaccine prospects. BJOG 122, 785-794. doi: 10.1111/1471-0528. 12994

Cassone, A. (2018). The case for an expanded concept of trained immunity. mBio 9:e00570-18. doi: 10.1128/mBio.00570-18
Cavalheiro, M., and Teixeira, M. C. (2018). Candida biofilms: threats, challenges, and promising strategies. Front. Med. 5:28. doi: 10.3389/fmed.2018.00028

Černáková, L., Light, C., Salehi, B., Rogel-Castillo, C., Victoriano, M., Martorell, M., et al. (2019). Novel therapies for biofilm-based Candida spp. infections. $A d v$. Exp. Med. Biol. 1214, 93-123. doi: 10.1007/5584_2019_400

Chandra, J., and Mukherjee, P. K. (2015). Candida biofilms: development, architecture, and resistance. Microbiol. Spectr. 3:10.1128/microbiolsec.MB0020-2015. doi: 10.1128/microbiolspec.MB-0020-2015

Chatterjee, S., Alampalli, S. V., Nageshan, R. K., Chettiar, S. T., Joshi, S., and Tatu, U. S. (2015). Draft genome of a commonly misdiagnosed multidrug resistant pathogen Candida auris. BMC Genomics 16:686. doi: 10.1186/s12864015-1863-z

Chen, C. G., Yang, Y. L., Tseng, K. Y., Shih, H. I., Liou, C. H., Lin, C. C., et al. (2009). Rep1p negatively regulating MDR1 efflux pump involved in drug resistance in Candida albicans. Fungal Genet. Biol. 46, 714-720. doi: 10.1016/j.fgb.2009.06. 003

Chowdhary, A., Prakash, A., Sharma, C., Kordalewska, M., Kumar, A., Sarma, S., et al. (2018). A multicentre study of antifungal susceptibility patterns among 350 Candida auris isolates (2009-17) in India: role of the ERG11 and FKS1 genes in azole and echinocandin resistance. J. Antimicrob. Chemother. 73, 891-899. doi: 10.1093/jac/dkx480

Connolly, L. A., Riccombeni, A., Grózer, Z., Holland, L. M., Lynch, D. B., Andes, D. R., et al. (2013). The APSES transcription factor Efg1 is a global regulator that controls morphogenesis and biofilm formation in Candida parapsilosis. Mol. Microbiol. 90, 36-53. doi: $10.1111 / \mathrm{mmi} .12345$

Conti, H. R., Shen, F., Nayyar, N., Stocum, E., Sun, J. N., Lindemann, M. J., et al. (2009). Th17 cells and IL-17 receptor signaling are essential for mucosal host defense against oral candidiasis. J. Exp. Med. 206, 299-311. doi: 10.1084/jem. 20081463

Corsello, S., Spinillo, A., Osnengo, G., Penna, C., Guaschino, S., Beltrame, A., et al. (2003). An epidemiological survey of vulvovaginal candidiasis in Italy. Eur J Obstet. Gynecol. Reprod. Biol. 110, 66-72. doi: 10.1016/s0301-2115(03)00096-4

Costa, M., Silva, A., Silva, A., Lima, V., Bezerra-Silva, P. C., Rocha, S., et al. (2017). Essential oils from leaves of medicinal plants of Brazilian flora: chemical composition and activity against Candida species. Medicines 4:27. doi: 10.3390/ medicines 4020027

Cota, E., and Hoyer, L. L. (2015). The Candida albicans agglutinin-like sequence family of adhesins: functional insights gained from structural analysis. Fut. Microbiol. 10, 1635-1548. doi: 10.2217/fmb.15.79

Cui, J., Ren, B., Tong, Y., Dai, H., and Zhang, L. (2015). Synergistic combinations of antifungals and anti-virulence agents to fight against Candida albicans. Virulence 6, 362-371. doi: 10.1080/21505594.2015.1039885

Dabiri, S., Shams-Ghahfarokhi, M., and Razzaghi-Abyaneh, M. (2018). Comparative analysis of proteinase, phospholipase, hydrophobicity and biofilm forming ability in Candida species isolated from clinical specimens. J. Mycol. Med. 28, 437-442. doi: 10.1016/j.mycmed.2018.04.009

Davani-Davari, D., Negahdaripour, M., Karimzadeh, I., Seifan, M., Mohkam, M., Masoumi, S. J., et al. (2019). Prebiotics: definition, types, sources, mechanisms, and clinical applications. Foods 8:92. doi: 10.3390/foods8030092

Denning, D. W., Kneale, M., Sobel, J. D., and Rautemaa-Richardson, R. (2018). Global burden of recurrent vulvovaginal candidiasis: a systematic review. Lancet. Infect. Dis. 18, e339-e347. doi: 10.1016/S1473-3099(18) 30103-8

de Barros, P. P., Rossoni, R. D., de Souza, C. M., Scorzoni, L., Fenley, J. C., and Junqueira, J. C. (2020). Candida biofilms: an update on developmental mechanisms and therapeutic challenges. Mycopathologia 185, 415-424. doi: 10.1007/s11046-020-00445-w

de Oliveira, D., Silva, L. B., da Silva, B. V., Borges, T. C., Marques, B. C., Dos Santos, M. B., et al. (2019). A new acridone with antifungal properties against Candida spp. and dermatophytes, and antibiofilm activity against C. albicans. J. Appl. Microbiol. 127, 1362-1372. doi: 10.1111/jam.14381

de Souza, T. B., Brito, K. M., Silva, N. C., Rocha, R. P., de Sousa, G. F., Duarte, L. P., et al. (2016). New eugenol glucoside-based derivative shows fungistatic and fungicidal activity against opportunistic Candida glabrata. Chem. Biol. Drug Des. 87, 83-90. doi: 10.1111/cbdd.12625

Diezmann, S., Leach, M. D., and Cowen, L. E. (2015). Functional divergence of Hsp90 genetic interactions in biofilm and planktonic cellular states. PLoS One 10:e0137947. doi: 10.1371/journal.pone.0137947 
Dižová, S., and Bujdáková, H. (2017). Properties and role of the quorum sensing molecule farnesol in relation to the yeast Candida albicans. Die Pharm. 72, 307-312. doi: 10.1691/ph.2017.6174

Djohan, V., Angora, K. E., Vanga-Bosson, A. H., Konaté, A., Kassi, K. F., KikiBarro, P., et al. (2019). Recurrent vulvo-vaginal candidiasis in Abidjan (Côte d'Ivoire): aetiology and associated factors. J. Mycol. Med. 29, 127-131. doi: 10.1016/j.mycmed.2019.04.002

Doerflinger, S. Y., Throop, A. L., and Herbst-Kralovetz, M. M. (2014). Bacteria in the vaginal microbiome alter the innate immune response and barrier properties of the human vaginal epithelia in a species-specific manner. J. Infect. Dis. 209, 1989-1999. doi: 10.1093/infdis/jiu004

Dominguez, E., Zarnowski, R., Sanchez, H., Covelli, A. S., Westler, W. M., Azadi, P., et al. (2018). Conservation and divergence in the Candida species biofilm matrix mannan-glucan complex structure, function, and genetic control. mBio 9:e00451-18. doi: 10.1128/mBio.00451-18

Duggan, S., Leonhardt, I., Hünniger, K., and Kurzai, O. (2015). Host response to Candida albicans bloodstream infection and sepsis. Virulence 6, 316-326. doi: 10.4161/21505594.2014.988096

El-Houssaini, H. H., Elnabawy, O. M., Nasser, H. A., and Elkhatib, W. F. (2019). Correlation between antifungal resistance and virulence factors in Candida albicans recovered from vaginal specimens. Microb. Pathog. 128, 13-19. doi: 10.1016/j.micpath.2018.12.028

Fan, Y., He, H., Dong, Y., and Pan, H. (2013). Hyphae-specific genes HGC1, ALS3, HWP1, and ECE1 and relevant signaling pathways in Candida albicans. Mycopathologia 176, 329-335. doi: 10.1007/s11046-013-9684-6

Feng, W., Yang, J., Pan, Y., Xi, Z., Qiao, Z., and Ma, Y. (2016). The correlation of virulence, pathogenicity, and itraconazole resistance with SAP activity in Candida albicans strains. Can. J. Microbiol. 62, 173-178. doi: 10.1139/cjm2015-0457

Fernandes, L., Oliveira, A., Henriques, M., and Rodrigues, M. E. (2020). Honey as a strategy to fight Candida tropicalis in mixed-biofilms with Pseudomonas aeruginosa. Antibiotics 9:43. doi: 10.3390/antibiotics9020043

Finkel, J. S., Xu, W., Huang, D., Hill, E. M., Desai, J. V., Woolford, C. A., et al. (2012). Portrait of Candida albicans adherence regulators. PLoS Pathog. 8:e1002525. doi: 10.1371/journal.ppat.1002525

Flemming, H. C., and Wingender, J. (2010). The biofilm matrix. Nat. Rev. Microbiol. 8, 623-633. doi: 10.1038/nrmicro2415

Fosso, M. Y., Shrestha, S. K., Thamban Chandrika, N., Dennis, E. K., Green, K. D., and Garneau-Tsodikova, S. (2018). Differential effects of linkers on the activity of amphiphilic tobramycin antifungals. Molecules 23:899. doi: 10.3390/ molecules23040899

Freire, F., de Barros, P. P., Pereira, C. A., Junqueira, J. C., and Jorge, A. (2018). Photodynamic inactivation in the expression of the Candida albicans genes ALS3, HWP1, BCR1, TEC1, CPH1, and EFG1 in biofilms. Lasers Med. Sci. 33, 1447-1454. doi: 10.1007/s10103-018-2487-8

Gabrielli, E., Pericolini, E., Ballet, N., Roselletti, E., Sabbatini, S., Mosci, P., et al. (2018). Saccharomyces cerevisiae-based probiotic as novel anti-fungal and antiinflammatory agent for therapy of vaginal candidiasis. Benef. Microbes 9, 219-230. doi: 10.3920/BM2017.0099

Ganguly, S., Bishop, A. C., Xu, W., Ghosh, S., Nickerson, K. W., Lanni, F., et al. (2011). Zap1 control of cell-cell signaling in Candida albicans biofilms. Eukaryot. Cell 10, 1448-1454. doi: 10.1128/EC.05196-11

Ghasemi, M., Etemadi, A., Nedaei, M., Chiniforush, N., and Pourhajibagher, M. (2019). Antimicrobial efficacy of photodynamic therapy using two different light sources on the titanium-adherent biofilms of Aggregatibacter actinomycetemcomitans: an in vitro study. Photodiagn. Photodyn. Ther. 26, 85-89. doi: 10.1016/j.pdpdt.2019.03.004

Gille, C., Böer, B., Marschal, M., Urschitz, M. S., Heinecke, V., Hund, V., et al. (2016). Effect of probiotics on vaginal health in pregnancy. EFFPRO, a randomized controlled trial. Am. J. Obstet. Gynecol. 215, 608.e1-608.e7. doi: 10.1016/j.ajog.2016.06.021

Glazier, V. E., Murante, T., Murante, D., Koselny, K., Liu, Y., Kim, D., et al. (2017). Genetic analysis of the Candida albicans biofilm transcription factor network using simple and complex haploinsufficiency. PLoS Genet. 13:e1006948. doi: 10.1371/journal.pgen.1006948

Gonçalves, B., Ferreira, C., Alves, C. T., Henriques, M., Azeredo, J., and Silva, S. (2016). Vulvovaginal candidiasis: epidemiology, microbiology and risk factors. Crit. Rev. Microbiol. 42, 905-927. doi: 10.3109/1040841X.2015.1091805
Gu, W., Xu, D., and Sun, S. (2015). In vitro models to study Candida albicans biofilms. J. Pharm. Drug Dev. 3:301. doi: 10.15744/2348-9782.3.301

Guan, G., Xie, J., Tao, L., Nobile, C. J., Sun, Y., Cao, C., et al. (2013). Bcr1 plays a central role in the regulation of opaque cell filamentation in Candida albicans. Mol. Microbiol. 89, 732-750. doi: 10.1111/mmi.12310

Gulati, M., and Nobile, C. J. (2016). Candida albicans biofilms: development, regulation, and molecular mechanisms. Microbes Infect. 18, 310-321. doi: 10. 1016/j.micinf.2016.01.002

Guzel, A. B., Ilkit, M., Akar, T., Burgut, R., and Demir, S. C. (2011). Evaluation of risk factors in patients with vulvovaginal candidiasis and the value of chromID Candida agar versus CHROMagar Candida for recovery and presumptive identification of vaginal yeast species. Med. Mycol. 49, 16-25. doi: 10.3109/ 13693786.2010.497972

Hall, C. L., and Lee, V. T. (2018). Cyclic-di-GMP regulation of virulence in bacterial pathogens. Wiley Interdiscip. Rev. RNA 9:10.1002/wrna.1454. doi: 10 . 1002/wrna.1454

Handalishy, I. I., Behery, M. A., Elkhouly, M., Farag, E. A., and Elsheikh, W. A. (2014). Comparative study between probiotic vaginal tampons and oral metronidazole in treatmentof bacterial vaginosis. Al_Azhar. Assiut. Med.J. 12(Suppl. 2), 185-203.

Harriott, M. M., Lilly, E. A., Rodriguez, T. E., Fidel, P. L., and Noverr, M. C. (2010). Candida albicans forms biofilms on the vaginal mucosa. Microbiology 156(Pt 12), 3635-3644. doi: 10.1099/mic.0.039354-0

Harrison, J. J., Ceri, H., Yerly, J., Rabiei, M., Hu, Y., Martinuzzi, R., et al. (2007a). Metal ions may suppress or enhance cellular differentiation in Candida albicans and Candida tropicalis biofilms. Appl. Environ. Microbiol. 73, 4940-4949. doi: 10.1128/AEM.02711-06

Harrison, J. J., Turner, R. J., and Ceri, H. (2007b). A subpopulation of Candida albicans and Candida tropicalis biofilm cells are highly tolerant to chelating agents. FEMS Microbiol. Lett. 272, 172-181. doi: 10.1111/j.1574-6968.2007. 00745.x

Hewadmal, N., and Jangra, S. (2019). A review on probiotic and health benefits of probiotics. Int. J. Curr. Microbiol. Appl. Sci. 8, 1863-1880. doi: 10.20546/ijcmas. 2019.805.218

Hirota, K., Yumoto, H., Sapaar, B., Matsuo, T., Ichikawa, T., and Miyake, Y. (2017). Pathogenic factors in Candida biofilm-related infectious diseases. J. Appl. Microbiol. 122, 321-330. doi: 10.1111/jam.13330

Holland, L. M., Schröder, M. S., Turner, S. A., Taff, H., Andes, D., Grózer, Z., et al. (2014). Comparative phenotypic analysis of the major fungal pathogens Candida parapsilosis and Candida albicans. PLoS Pathog. 10:e1004365. doi: 10.1371/journal.ppat.1004365

Hoque, J., Akkapeddi, P., Yadav, V., Manjunath, G. B., Uppu, D. S., Konai, M. M., et al. (2015). Broad spectrum antibacterial and antifungal polymeric paint materials: synthesis, structure-activity relationship, and membrane-active mode of action. ACS Appl. Mater. Interfaces 7, 1804-1815. doi: 10.1021/am507482y

Hu, J., Guan, G., Dai, Y., Tao, L., Zhang, J., Li, H., et al. (2016). Phenotypic diversity and correlation between white-opaque switching and the CAI microsatellite locus in Candida albicans. Curr. Genet. 62, 585-593. doi: 10.1007/s00294-0160564-8

Ichikawa, T., Kutsumi, Y., Sadanaga, J., Ishikawa, M., Sugita, D., and Ikeda, R. (2019). Adherence and cytotoxicity of Candida spp. to HaCaT and A549 cells. Med. Mycol. J. 60, 5-10. doi: 10.3314/mmj.18-00011

Inglis, D. O., and Sherlock, G. (2013). Ras signaling gets fine-tuned: regulation of multiple pathogenic traits of Candida albicans. Eukaryot. Cell 12, 1316-1325. doi: 10.1128/EC.00094-13

Jaeger, M., Plantinga, T. S., Joosten, L. A., Kullberg, B. J., and Netea, M. G. (2013). Genetic basis for recurrent vulvo-vaginal candidiasis. Curr. Infect. Dis. Rep. 15, 136-142. doi: 10.1007/s11908-013-0319-3

Jiang, L., Wang, J., Asghar, F., Snyder, N., and Cunningham, K. W. (2018). CaGdt1 plays a compensatory role for the calcium pump CaPmrl in the regulation of calcium signaling and cell wall integrity signaling in Candida albicans. Cell Commun. Signal. 16:33. doi: 10.1186/s12964-018-0246-x

Joseph, M. R., Al-Hakami, A. M., Assiry, M. M., Jamil, A. S., Assiry, A. M., Shaker, M. A., et al. (2015). In vitro anti-yeast activity of chloramphenicol: a preliminary report. J. Mycol. Med. 25, 17-22. doi: 10.1016/j.mycmed.2014.10.019

Kadry, A. A., El-Ganiny, A. M., and El-Baz, A. M. (2018). Relationship between Sap prevalence and biofilm formation among resistant clinical isolates of Candida albicans. Afr. Health Sci. 18, 1166-1174. doi: 10.4314/ahs.v18i4.37 
Kalaiarasan, K., Singh, R., and Chaturvedula, L. (2018). Changing virulence factors among vaginal non-albicans Candida species. Indian J. Med. Microbiol. 36, 364-368. doi: 10.4103/ijmm.IJMM_18_94

Kalia, N., Singh, J., and Kaur, M. (2019). Immunopathology of recurrent vulvovaginal infections: new aspects and research directions. Front. Immunol. 10:2034. doi: 10.3389/fimmu.2019.02034

Karkowska-Kuleta, J., Satala, D., Bochenska, O., Rapala-Kozik, M., and Kozik, A. (2019). Moonlighting proteins are variably exposed at the cell surfaces of Candida glabrata, Candida parapsilosis and Candida tropicalis under certain growth conditions. BMC Microbiol. 19:149. doi: 10.1186/s12866-019-1524-5

Khosravi Rad, K., Falahati, M., Roudbary, M., Farahyar, S., and Nami, S. (2016). Overexpression of MDR-1 and CDR-2 genes in fluconazole resistance of Candida albicans isolated from patients with vulvovaginal candidiasis. Curr. Med. Mycol. 2, 24-29. doi: 10.18869/acadpub.cmm.2.4.24

Köhler, G. A., Assefa, S., and Reid, G. (2012). Probiotic interference of Lactobacillus rhamnosus GR-1 and Lactobacillus reuteri RC-14 with the opportunistic fungal pathogen Candida albicans. Infect. Dis. Obstet. Gynecol. 2012, 636474. doi: $10.1155 / 2012 / 636474$

Kovács, R., Nagy, F., Tóth, Z., Bozó, A., Balázs, B., and Majoros, L. (2019). Synergistic effect of nikkomycin $\mathrm{Z}$ with caspofungin and micafungin against Candida albicans and Candida parapsilosis biofilms. Lett. Appl. Microbiol. 69, 271-278. doi: 10.1111/lam.13204

Kumar, D., Banerjee, T., Pratap, C. B., and Tilak, R. (2015). Itraconazole-resistant Candida auris with phospholipase, proteinase and hemolysin activity from a case of vulvovaginitis. J. Infect. Dev. Ctries 9, 435-437. doi: 10.3855/jidc. 4582

Leiva-Peláez, O., Gutiérrez-Escobedo, G., López-Fuentes, E., Cruz-Mora, J., De Las Peñas, A., and Castaño, I. (2018). Molecular characterization of the silencing complex SIR in Candida glabrata hyperadherent clinical isolates. Fungal Genet. Biol. 118, 21-31. doi: 10.1016/j.fgb.2018.05.005

Leonhard, V., Alasino, R. V., Munoz, A., and Beltramo, D. M. (2018). Silver nanoparticles with high loading capacity of amphotericin B: characterization, bactericidal and antifungal effects. Curr. Drug Deliv. 15, 850-859. doi: 10.2174/ 1567201814666170918162337

Li, X., Wu, B., Chen, H., Nan, K., Jin, Y., Sun, L., et al. (2018). Recent developments in smart antibacterial surfaces to inhibit biofilm formation and bacterial infections. J. Mater. Chem. B 6, 4274-4292. doi: 10.1039/c8tb01245h

Li, X., Zhao, Y., Huang, X., Yu, C., Yang, Y., and Sun, S. (2017). Ambroxol hydrochloride combined with fluconazole reverses the resistance of Candida albicans to fluconazole. Front. Cell Infect Microbiol. 7:124. doi: 10.3389/fcimb. 2017.00124

Lindsay, A. K., Deveau, A., Piispanen, A. E., and Hogan, D. A. (2012). Farnesol and cyclic AMP signaling effects on the hypha-to-yeast transition in Candida albicans. Eukaryot. Cell 11, 1219-1225. doi: 10.1128/EC.00144-12

Liu, Y., and Filler, S. G. (2011). Candida albicans Als3, a multifunctional adhesin and invasin. Eukaryot. Cell 10, 168-173. doi: 10.1128/EC.00279-10

Madende, M., Albertyn, J., Sebolai, O., and Pohl, C. H. (2020). Caenorhabditis elegans as a model animal for investigating fungal pathogenesis. Med. Microbiol. Immunol. 209, 1-13. doi: 10.1007/s00430-019-00635-4

Mahmoudi Rad, M., Zafarghandi, S., Abbasabadi, B., and Tavallaee, M. (2011). The epidemiology of Candida species associated with vulvovaginal candidiasis in an Iranian patient population. Eur. J. Obstet. Gynecol. Reprod. Biol. 155, 199-203. doi: 10.1016/j.ejogrb.2010.11.022

Marak, M. B., and Dhanashree, B. (2018). Antifungal susceptibility and biofilm production of Candida spp. isolated from clinical samples. Int. J. Microbiol. 2018:7495218. doi: 10.1155/2018/7495218

Maraki, S., Mavromanolaki, V. E., Stafylaki, D., Nioti, E., Hamilos, G., and Kasimati, A. (2019). Epidemiology and antifungal susceptibility patterns of Candida isolates from Greek women with vulvovaginal candidiasis. Mycoses 62, 692-697. doi: 10.1111/myc.12946

Martins, N., Ferreira, I. C. F. R., Henriques, M., and Silva, S. (2016). In vitro anti-Candida activity of Glycyrrhiza glabra L. Ind. Crop. Prod. 83, 81-85. doi: 10.1016/j.indcrop.2015.12.029

Mathé, L., and Van Dijck, P. (2013). Recent insights into Candida albicans biofilm resistance mechanisms. Curr. Genet. 59, 251-264. doi: 10.1007/s00294-0130400-3

McCall, A. D., Kumar, R., and Edgerton, M. (2018). Candida albicans Sfl1/Sfl2 regulatory network drives the formation of pathogenic microcolonies. PLoS Pathog. 14:e1007316. doi: 10.1371/journal.ppat.1007316
McCall, A. D., Pathirana, R. U., Prabhakar, A., Cullen, P. J., and Edgerton, M. (2019). Candida albicans biofilm development is governed by cooperative attachment and adhesion maintenance proteins. NPJ Biofilms Microbiomes 5:21. doi: 10.1038/s41522-019-0094-5

Mehmood, A., Liu, G., Wang, X., Meng, G., Wang, C., and Liu, Y. (2019). Fungal quorum-sensing molecules and inhibitors with potential antifungal activity: a review. Molecules 24:1950. doi: 10.3390/molecules 24101950

Mendelsohn, S., Pinsky, M., Weissman, Z., and Kornitzer, D. (2017). Regulation of the Candida albicans hypha-inducing transcription factor Ume6 by the CDK1 cyclins Cln3 and Hgc1. mSphere 2:e00248-16. doi: 10.1128/mSphere.00248-16

Min, K., Biermann, A., Hogan, D. A., and Konopka, J. B. (2018). Genetic analysis of NDT80 family transcription factors in Candida albicans using new CRISPRCas9 approaches. $m$ Sphere 3:e00545-18. doi: 10.1128/mSphere.00545- 18

Min, K., Naseem, S., and Konopka, J. B. (2019). N-acetylglucosamine regulates morphogenesis and virulence pathways in fungi. J. Fungi 6:E8. doi: 10.3390/ jof6010008

Mina, E. G., and Marques, C. N. (2016). Interaction of Staphylococcus aureus persister cells with the host when in a persister state and following awakening. Sci. Rep. 6:31342. doi: 10.1038/srep31342

Miró, M. S., Rodríguez, E., Vigezzi, C., Icely, P. A., Gonzaga de Freitas-Araújo, M., Riera, F. O., et al. (2017). Vulvovaginal candidiasis: an old disease with new challenges. Rev. Iberoam. Micol. 34, 65-71. doi: 10.1016/j.riam.2016. 11.006

Mitchell, K. F., Zarnowski, R., Sanchez, H., Edward, J. A., Reinicke, E. L., Nett, J. E., et al. (2015). Community participation in biofilm matrix assembly and function. Proc. Natl. Acad. Sci. U.S.A. 112, 4092-4097. doi: 10.1073/pnas.14214 37112

Miyazima, T. Y., Ishikawa, K. H., Mayer, M., Saad, S., and Nakamae, A. (2017). Cheese supplemented with probiotics reduced the Candida levels in denture wearers-RCT. Oral Dis. 23, 919-925. doi: 10.1111/odi.12669

Modrzewska, B., and Kurnatowski, P. (2015). Adherence of Candida sp. to host tissues and cells as one of its pathogenicity features. Ann. Parasitol. 61, 3-9.

Moher, D., Shamseer, L., Clarke, M., Ghersi, D., Liberati, A., Petticrew, M., et al. (2015). Preferred reporting items for systematic review and meta-analysis protocols (PRISMA-P) 2015 statement. Syst. Rev. 4:1. doi: 10.1186/2046-40534-1

Monika, S. (2019). Virulence factors in Candida species. Curr. Protein Pept. Sci. 21, 313-323. doi: 10.2174/1389203720666190722152415

Monteiro, D. R., Arias, L. S., Fernandes, R. A., Deszo da Silva, L. F., de Castilho, M., da Rosa, T. O., et al. (2017). Antifungal activity of tyrosol and farnesol used in combination against Candida species in the planktonic state or forming biofilms. J. Appl. Microbiol. 123, 392-400. doi: 10.1111/jam.13513

Muzny, C. A., and Schwebke, J. R. (2015). Biofilms: an underappreciated mechanism of treatment failure and recurrence in vaginal infections. Clin. Infect. Dis. 61, 601-606. doi: 10.1093/cid/civ353

Naglik, J. R., Fidel, P. L. Jr., and Odds, F. C. (2008). Animal models of mucosal Candida infection. FEMS Microbiol Lett. 283, 129-139. doi: 10.1111/j.15746968.2008.01160.x

Navarro-Arias, M. J., Defosse, T. A., Dementhon, K., Csonka, K., MelladoMojica, E., Dias Valério, A., et al. (2016). Disruption of protein mannosylation affects Candida guilliermondii cell wall, immune sensing, and virulence. Front. Microbiol. 7:1951. doi: 10.3389/fmicb.2016.01951

Negri, M., Silva, S., Henriques, M., Azeredo, J., Svidzinski, T., and Oliveira, R. (2011). Candida tropicalis biofilms: artificial urine, urinary catheters and flow model. Med. Mycol. 49, 739-747. doi: 10.3109/13693786.2011.560619

Neppelenbroek, K. H., Seó, R. S., Urban, V. M., Silva, S., Dovigo, L. N., Jorge, J. H., et al. (2014). Identification of Candida species in the clinical laboratory: a review of conventional, commercial, and molecular techniques. Oral dis. 20, 329-344. doi: 10.1111/odi.12123

Nett, J. E. (2016). The host's reply to Candida biofilm. Pathogens 5:33. doi: 10.3390/ pathogens5010033

Nett, J. E., Sanchez, H., Cain, M. T., Ross, K. M., and Andes, D. R. (2011). Interface of Candida albicans biofilm matrix-associated drug resistance and cell wall integrity regulation. Eukaryot. Cell 10, 1660-1669. doi: 10.1128/EC.05126-11

Nett, J. E., Zarnowski, R., Cabezas-Olcoz, J., Brooks, E. G., Bernhardt, J., Marchillo, K., et al. (2015). Host contributions to construction of three device-associated Candida albicans biofilms. Infect. Immun. 83, 4630-4638. doi: 10.1128/IAI. 00931-15 
Ng, H., and Dean, N. (2017). Dramatic improvement of CRISPR/Cas9 editing in Candida albicans by increased single guide RNA expression. mSphere 2:e0038516. doi: $10.1128 / \mathrm{mSphere} .00385-16$

Ni, L., Bruce, C., Hart, C., Leigh-Bell, J., Gelperin, D., Umansky, L., et al. (2009). Dynamic and complex transcription factor binding during an inducible response in yeast. Genes Dev. 23, 1351-1363. doi: 10.1101/gad.1781909

Ning, Y., Ling, J., and Wu, C. D. (2015). Synergistic effects of tea catechin epigallocatechin gallate and antimycotics against oral Candida species. Arch. Oral Biol. 60, 1565-1570. doi: 10.1016/j.archoralbio.2015.07.001

Nobile, C. J., Fox, E. P., Nett, J. E., Sorrells, T. R., Mitrovich, Q. M., Hernday, A. D., et al. (2012). A recently evolved transcriptional network controls biofilm development in Candida albicans. Cell 148, 126-138. doi: 10.1016/j.cell.2011. 10.048

Nweze, E. I., Ghannoum, A., Chandra, J., Ghannoum, M. A., and Mukherjee, P. K. (2012). Development of a 96-well catheter-based microdilution method to test antifungal susceptibility of Candida biofilms. J. Antimicrob. Chemother. 67, 149-153. doi: 10.1093/jac/dkr429

Olveira, G., and González-Molero, I. (2016). An update on probiotics, prebiotics and symbiotics in clinical nutrition. Endocrinol. Nutr. 63, 482-494. doi: 10. 1016/j.endonu.2016.07.006

Orsi, C. F., Borghi, E., Colombari, B., Neglia, R. G., Quaglino, D., Ardizzoni, A., et al. (2014). Impact of Candida albicans hyphal wall protein 1 (HWP1) genotype on biofilm production and fungal susceptibility to microglial cells. Microb. Pathog. 6, 20-27. doi: 10.1016/j.micpath.2014.03.003

Ozcan, K., Ilkit, M., Ates, A., Turac-Bicer, A., and Demirhindi, H. (2010). Performance of chromogenic Candida agar and CHROMagar Candida in recovery and presumptive identification of monofungal and polyfungal vaginal isolates. Med. Mycol. 48, 29-34. doi: 10.3109/13693780802713224

Padder, S. A., Prasad, R., and Shah, A. H. (2018). Quorum sensing: a less known mode of communication among fungi. Microbiol. Res. 210, 51-58. doi: 10.1016/ j.micres.2018.03.007

Palmieri, V., Bugli, F., Cacaci, M., Perini, G., Maio, F., Delogu, G., et al. (2018). Graphene oxide coatings prevent Candida albicans biofilm formation with a controlled release of curcumin-loaded nanocomposites. Nanomedicine 13, 2867-2879. doi: 10.2217/nnm-2018-0183

Paluch, E., Rewak-Soroczyńska, J., Jędrusik, I., Mazurkiewicz, E., and Jermakow, K. (2020). Prevention of biofilm formation by quorum quenching. Appl. Microbiol. Biotechnol. 104, 1871-1881. doi: 10.1007/s00253-020-10349-w

Pankey, G., Ashcraft, D., Kahn, H., and Ismail, A. (2014). Time-kill assay and etest evaluation for synergy with polymyxin B and fluconazole against Candida glabrata. Antimicrob. Agents Chemother. 58, 5795-5800. doi: 10.1128/AAC. 03035-14

Paulone, S., Ardizzoni, A., Tavanti, A., Piccinelli, S., Rizzato, C., Lupetti, A., et al. (2017). The synthetic killer peptide KP impairs Candida albicans biofilm in vitro. PLoS One 12:e181278. doi: 10.1371/journal.pone.0181278

Pericolini, E., Gabrielli, E., Amacker, M., Kasper, L., Roselletti, E., Luciano, E., et al. (2015). Secretory aspartyl proteinases cause vaginitis and can mediate vaginitis caused by Candida albicans in mice. mBio 6:e00724. doi: 10.1128/mBio.0072415

Peters, B. M., Yano, J., Noverr, M. C., and Fidel, P. L. Jr. (2014). Candida vaginitis: when opportunism knocks, the host responds. PLoS Pathog. 10:e1003965. doi: 10.1371/journal.ppat.1003965

Pierce, C. G., Vila, T., Romo, J. A., Montelongo-Jauregui, D., Wall, G., Ramasubramanian, A., et al. (2017). The Candida albicans biofilm matrix: composition, structure and function. J. Fungi 3:14. doi: 10.3390/jof3010014

Pohlers, S., Martin, R., Krüger, T., Hellwig, D., Hänel, F., Kniemeyer, O., et al. (2017). Lipid signaling via Pkh1/2 regulates fungal CO2 sensing through the kinase Sch9. mBio 8:e02211-16. doi: 10.1128/mBio.02211-16

Polke, M., Leonhardt, I., Kurzai, O., and Jacobsen, I. D. (2018). Farnesol signalling in Candida albicans - more than just communication. Crit. Rev. Microbiol. 44, 230-243. doi: 10.1080/1040841X.2017.1337711

Raman, N., Lee, M. R., Lynn, D. M., and Palecek, S. P. (2015). Antifungal activity of 14 -Helical $\beta$-peptides against planktonic cells and biofilms of Candida Species. Pharmaceuticals 8, 483-503. doi: 10.3390/ph8030483

Richardson, J. P., Willems, H., Moyes, D. L., Shoaie, S., Barker, K. S., Tan, S. L., et al. (2018). Candidalysin drives epithelial signaling, neutrophil recruitment, and immunopathology at the vaginal mucosa. Infect. Immun. 86:e00645-17. doi: 10.1128/IAI.00645-17
Richmond, G. S., and Smith, T. K. (2011). Phospholipases A $A_{1}$ Int. J. Mol. Sci. 12, 588-612. doi: 10.3390/ijms12010588

Riekhof, W. R., and Nickerson, K. W. (2017). Quorum sensing in Candida albicans: farnesol versus farnesoic acid. FEBS Lett. 591, 1637-1640. doi: 10.1002/18733468.12694

Rodríguez-Cerdeira, C., Gregorio, M. C., Molares-Vila, A., López-Barcenas, A., Fabbrocini, G., Bardhi, B., et al. (2019). Biofilms and vulvovaginal candidiasis. Coll. Surf. B Biointerfaces 174, 110-125. doi: 10.1016/j.colsurfb.2018.11.011

Samaranayake, Y. H., Ye, J., Yau, J. Y., Cheung, B. P., and Samaranayake, L. P. (2005). In vitro method to study antifungal perfusion in Candida biofilms. J. Clin. Microbiol. 43, 818-825. doi: 10.1128/JCM.43.2.818-825.2005

Saxena, P., Joshi, Y., Rawat, K., and Bisht, R. (2019). Biofilms: architecture, resistance, quorum sensing and control mechanisms. Indian J. Microbiol. 59, 3-12. doi: 10.1007/s12088-018-0757-6

Schaller, M., Bein, M., Korting, H. C., Baur, S., Hamm, G., Monod, M., et al. (2003). The secreted aspartyl proteinases Sap1 and Sap2 cause tissue damage in an in vitro model of vaginal candidiasis based on reconstituted human vaginal epithelium. Infect. Immun. 71, 3227-3234. doi: 10.1128/iai.71.6.32273234.2003

Schaller, M., Korting, H. C., Borelli, C., Hamm, G., and Hube, B. (2005). Candida albicans-secreted aspartic proteinases modify the epithelial cytokine response in an in vitro model of vaginal candidiasis. Infect. Immun. 73, 2758-2765. doi: 10.1128/IAI.73.5.2758-2765.2005

Seleem, D., Benso, B., Noguti, J., Pardi, V., and Murata, R. M. (2016). In vitro and in vivo antifungal activity of lichochalcone-A against Candida albicans biofilms. PLoS One 11:e0157188. doi: 10.1371/journal.pone.0157188

Shao, J., Lu, K., Tian, G., Cui, Y., Yan, Y., Wang, T., et al. (2015). Labscale preparations of Candida albicans and dual Candida albicans-Candida glabrata biofilms on the surface of medical-grade polyvinyl chloride (PVC) perfusion tube using a modified gravity-supported free-flow biofilm incubator (GS-FFBI). J. Microbiol. Methods 109, 41-48. doi: 10.1016/j.mimet.2014. 12.006

Sharma, M., Biswas, D., Kotwal, A., Thakuria, B., Kakati, B., Chauhan, B. S., et al. (2015). Ibuprofen-mediated reversal of fluconazole resistance in clinical isolates of Candida. J. Clin. Diagn. Res. 9, DC20-DC22. doi: 10.7860/JCDR/2015/10094. 5494

Shrestha, S. K., Garzan, A., and Garneau-Tsodikova, S. (2017). Novel alkylated azoles as potent antifungals. Eur. J. Med. Chem. 133, 309-318. doi: 10.1016/j. ejmech.2017.03.075

Shukla, A., and Sobel, J. D. (2019). Vulvovaginitis caused by Candida species following antibiotic exposure. Curr. Infect. Dis. Rep. 21:44. doi: 10.1007/s11908019-0700-y

Silva, N. C., Nery, J. M., and Dias, A. L. (2014). Aspartic proteinases of Candida spp.: role in pathogenicity and antifungal resistance. Mycoses 57, 1-11. doi: $10.1111 /$ myc. 12095

Silva, S., Negri, M., Henriques, M., Oliveira, R., Williams, D. W., and Azeredo, J. (2012). Candida glabrata, Candida parapsilosis and Candida tropicalis: biology, epidemiology, pathogenicity and antifungal resistance. FEMS Microbiol. Rev. 36, 288-305. doi: 10.1111/j.1574-6976.2011.00278.x

Silva-Dias, A., Miranda, I. M., Branco, J., Cobrado, L., Monteiro-Soares, M., Pina-Vaz, C., et al. (2015). In vitro antifungal activity and in vivo antibiofilm activity of cerium nitrate against Candida species. J. Antimicrob. Chemother. 70, 1083-1093. doi: 10.1093/jac/dku511

Smith, S. B., and Ravel, J. (2017). The vaginal microbiota, host defence and reproductive physiology. J. Physiol. 595, 451-463. doi: 10.1113/JP271694

Sobel, J. D. (2007). Vulvovaginal candidosis. Lancet 369, 1961-1971. doi: 10.1016/ S0140-6736(07)60917-9

Srinivasan, A., Leung, K. P., Lopez-Ribot, J. L., and Ramasubramanian, A. K. (2013). High-throughput nano-biofilm microarray for antifungal drug discovery. mBio 4:e00331-13. doi: 10.1128/mBio.00331-13

Srinivasan, A., Lopez-Ribot, J. L., and Ramasubramanian, A. K. (2012). Candida albicans biofilm chip (CaBChip) for high-throughput antifungal drug screening. J. Vis. Exp. e3845. doi: 10.3791/3845

Stergiopoulou, T., Meletiadis, J., Sein, T., Papaioannidou, P., Tsiouris, I., Roilides, E., et al. (2009). Comparative pharmacodynamic interaction analysis between ciprofloxacin, moxifloxacin and levofloxacin and antifungal agents against Candida albicans and Aspergillus fumigatus. J. Antimicrob. Chemother. 63, 343-348. doi: 10.1093/jac/dkn473 
Stoddart, C. A., Maidji, E., Galkina, S. A., Kosikova, G., Rivera, J. M., Moreno, B. R., et al. (2011). Superior human leukocyte reconstitution and susceptibility to vaginal HIV transmission in humanized NOD-scid IL-2R $\gamma(-/-)$ (NSG) BLT mice. Virology 417, 154-160. doi: 10.1016/j.virol.2011.05.013

Su, C., Yu, J., and Lu, Y. (2018). Hyphal development in Candida albicans from different cell states. Curr. Genet. 64, 1239-1243. doi: 10.1007/s00294-018-08455

Sui, X., Yan, L., and Jiang, Y. Y. (2017). The vaccines and antibodies associated with Als3p for treatment of Candida albicans infections. Vaccine 35, 5786-5793. doi: $10.1016 /$ j.vaccine.2017.08.082

Tan, Y., Leonhard, M., Ma, S., Moser, D., and Schneider-Stickler, B. (2017). Dispersal of single and mixed non-albicans Candida species biofilms by $\beta-1,3-$ glucanase in vitro. Microb. Pathog. 113, 342-347. doi: 10.1016/j.micpath.2017. 10.057

Tan, Y., Ma, S., Leonhard, M., Moser, D., and Schneider-Stickler, B. (2018). $\beta$-1,3glucanase disrupts biofilm formation and increases antifungal susceptibility of Candida albicans DAY185.ăInt. J. Biol.ă108, 942-946. doi: 10.1016/j.ijbiomac. 2017.11.003

Tanaka, Y., Sasaki, M., Ito, F., Aoyama, T., Sato-Okamoto, M., TakahashiNakaguchi, A., et al. (2016). KRE5 suppression induces cell wall stress and alternative ER stress response required for maintaining cell wall integrity in Candida glabrata. PLoS One 11:e0161371. doi: 10.1371/journal.pone.0161371

Tang, Y., Yu, F., Huang, L., and Hu, Z. (2019). The changes of antifungal susceptibilities caused by the phenotypic switching of Candida species in 229 patients with vulvovaginal candidiasis. J. Clin. Lab. Anal. 33:e22644. doi: 10. $1002 /$ jcla. 22644

Thamban Chandrika, N., Shrestha, S. K., Ngo, H. X., and Howard, K. C. (2018). Novel fluconazole derivatives with promising antifungal activity. Bioorg. Med. Chem. 26, 573-580. doi: 10.1016/j.bmc.2017.12.018

Theberge, S., Semlali, A., Alamri, A., Leung, K. P., and Rouabhia, M. (2013). C. albicans growth, transition, biofilm formation, and gene expression modulation by antimicrobial decapeptide KSL-W. BMC Microbiol. 13:246. doi: 10.1186/ 1471-2180-13-246

Thomas, D. P., Bachmann, S. P., and Lopez-Ribot, J. L. (2006). Proteomics for the analysis of the Candida albicans biofilm lifestyle. Proteomics 6, 5795-5804. doi: 10.1002/pmic. 200600332

Tournu, H., and Van Dijck, P. (2012). Candida biofilms and the host: models and new concepts for eradication. Int. J. Microbiol. 2012:845352. doi: 10.1155/2012/ 845352

Tsimaris, P., Giannouli, A., Tzouma, C., Athanasopoulos, N., Creatsas, G., and Deligeoroglou, E. (2019). Alleviation of vulvovaginitis symptoms: can probiotics lead the treatment plan? Benef. Microbes 10, 867-872. doi: 10.3920/ BM2019.0048

Tso, G., Reales-Calderon, J. A., and Pavelka, N. (2018). The elusive anti-Candida vaccine: lessons from the past and opportunities for the future. Front. Immunol. 9:897. doi: 10.3389/fimmu.2018.00897

Tsui, C., Kong, E. F., and Jabra-Rizk, M. A. (2016). Pathogenesis of Candida albicans biofilm. Pathog. Dis. 74:ftw018. doi: 10.1093/femspd/ftw018

Valotteau, C., Prystopiuk, V., Cormack, B. P., Dufrêne, Y. F., and Mitchell, A. P. (2019). Atomic force microscopy demonstrates that Candida glabrata uses three Epa proteins to mediate adhesion to abiotic surfaces. mSphere 4, e00277-19. doi: 10.1128/mSphere.00277-19

van de Wijgert, J., and Verwijs, M. C. (2020). Lactobacilli-containing vaginal probiotics to cure or prevent bacterial or fungal vaginal dysbiosis: a systematic review and recommendations for future trial designs. BJOG 127, 287-299. doi: 10.1111/1471-0528.15870

van Wijlick, L., Swidergall, M., Brandt, P., and Ernst, J. F. (2016). Candida albicans responds to glycostructure damage by Ace2-mediated feedback regulation of Cek1 signaling. Mol. Microbiol. 102, 827-849. doi: 10.1111/mmi.13494

Vandeputte, P., Pradervand, S., Ischer, F., Coste, A. T., Ferrari, S., Harshman, K., et al. (2012). Identification and functional characterization of Rcal, a transcription factor involved in both antifungal susceptibility and host response in Candida albicans. Eukaryot. Cell 11, 916-931. doi: 10.1128/EC.00134-12

Visek, J., Ryskova, L., Safranek, R., Lasticova, M., and Blaha, V. (2019). In vitro comparison of efficacy of catheter locks in the treatment of catheter related blood stream infection. Clin. Nutr. ESPEN 30, 107-112. doi: 10.1016/j.clnesp. 2019.01.010

Vogel, M., Hartmann, T., Köberle, M., Treiber, M., Autenrieth, I. B., and Schumacher, U. K. (2008). Rifampicin induces MDR1 expression in Candida albicans. J. Antimicrob. Chemother. 61, 541-547. doi: 10.1093/jac/dkm513
Wagener, J., Weindl, G., de Groot, P. W., de Boer, A. D., Kaesler, S., Thavaraj, S., et al. (2012). Glycosylation of Candida albicans cell wall proteins is critical for induction of innate immune responses and apoptosis of epithelial cells. PLoS One 7:e50518. doi: 10.1371/journal.pone.0050518

Walraven, C. J., and Lee, S. A. (2013). Antifungal lock therapy. Antimicrob. Agents Chemother. 57, 1-8. doi: 10.1128/AAC.01351-12

Wang, X., and Fries, B. C. (2011). A murine model for catheter-associated candiduria. J. Med. Microbiol. 60(Pt 10), 1523-1529. doi: 10.1099/jmm.0. 026294-0

Wilkins, M., Zhang, N., and Schmid, J. (2018). Biological roles of protein-coding tandem repeats in the yeast Candida albicans. J. Fungi 4:78. doi: 10.3390/ jof 4030078

Willaert, R. G. (2018). Adhesins of yeasts: protein structure and interactions. J. Fungi 4:119. doi: 10.3390/jof4040119

Willems, H., Lowes, D. J., Barker, K. S., Palmer, G. E., and Peters, B. M. (2018). Comparative analysis of the capacity of the Candida species to elicit vaginal immunopathology. Infect. Immun. 86:e00527-18. doi: 10.1128/IAI.00527- 18

Wuyts, J., Van Dijck, P., and Holtappels, M. (2018). Fungal persister cells: the basis for recalcitrant infections? PLoS Pathog. 14:e1007301. doi: 10.1371/journal.ppat. 1007301

Xie, Y., Liu, X., and Zhou, P. (2020). In vitro antifungal effects of berberine against Candida spp. in planktonic and biofilm conditions. Drug. Des. Devel. Ther. 14, 87-101. doi: 10.2147/DDDT.S230857

Yano, J., and Fidel, P. L. Jr. (2011). Protocols for vaginal inoculation and sample collection in the experimental mouse model of Candida vaginitis. J. Vis. Exp. 8:3382. doi: $10.3791 / 3382$

Yano, J., Noverr, M. C., and Fidel, P. L. Jr. (2012). Cytokines in the host response to Candida vaginitis: identifying a role for non-classical immune mediators, $\$ 100$ alarmins. Cytokine 58, 118-128. doi: 10.1016/j.cyto.2011.11.021

Yano, J., Peters, B. M., Noverr, M. C., and Fidel, P. L. Jr. (2018). Novel mechanism behind the immunopathogenesis of vulvovaginal candidiasis: "neutrophil anergy". Infect. Immun. 86, e684-e617. doi: 10.1128/IAI.00684-17

Yano, J., Sobel, J. D., Nyirjesy, P., Sobel, R., Williams, V. L., Yu, Q., et al. (2019). Current patient perspectives of vulvovaginal candidiasis: incidence, symptoms, management and post-treatment outcomes. BMC Womens Health 19:48. doi: 10.1186/s12905-019-0748-8

Yu, J. J., and Gaffen, S. L. (2008). Interleukin-17: a novel inflammatory cytokine that bridges innate and adaptive immunity. Front. Biosci. 13:170-177. doi: $10.2741 / 2667$

Zajac, D., Karkowska-Kuleta, J., Bochenska, O., Rapala-Kozik, M., and Kozik, A. (2016). Interaction of human fibronectin with Candida glabrata epithelial adhesin 6 (Epa6). Acta Biochim. Pol. 63, 417-426. doi: 10.18388/abp.2016_1328

Zarnowski, R., Westler, W. M., Lacmbouh, G. A., Marita, J. M., Bothe, J. R., Bernhardt, J., et al. (2014). Novel entries in a fungal biofilm matrix encyclopedia. mBio 5:e01333-14. doi: 10.1128/mBio.01333-14

Zhao, S., Huang, J. J., Sun, X., Huang, X., Fu, S., Yang, L., et al. (2018). (1-aryloxy-2-hydroxypropyl)-phenylpiperazine derivatives suppress Candida albicans virulence by interfering with morphological transition. Microb. Biotechnol. 11, 1080-1089. doi: 10.1111/1751-7915.13307

Zhao, X., Pujol, C., Soll, D. R., and Hoyer, L. L. (2003). Allelic variation in the contiguous loci encoding Candida albicans ALS5, ALS1 and ALS9. Microbiology 149(Pt 10), 2947-2960. doi: 10.1099/mic.0. 26495-0

Zhou, Y., Wang, G., Li, Y., Liu, Y., Song, Y., Zheng, W., et al. (2012). In vitro interactions between aspirin and amphotericin $B$ against planktonic cells and biofilm cells of Candida albicans and C. parapsilosis. Antimicrob. Agents Chemother. 56, 3250-3260. doi: 10.1128/AAC. 06082-11

Conflict of Interest: The authors declare that the research was conducted in the absence of any commercial or financial relationships that could be construed as a potential conflict of interest.

Copyright $\odot 2020$ Rodríguez-Cerdeira, Martínez-Herrera, Carnero-Gregorio, LópezBarcenas, Fabbrocini, Fida, El-Samahy and González-Cespón. This is an open-access article distributed under the terms of the Creative Commons Attribution License (CC BY). The use, distribution or reproduction in other forums is permitted, provided the original author(s) and the copyright owner(s) are credited and that the original publication in this journal is cited, in accordance with accepted academic practice. No use, distribution or reproduction is permitted which does not comply with these terms. 